\title{
A Mobile Sensing Approach to Stress Detection and Memory Activation for Public Bus Drivers
}

\author{
João G. P. Rodrigues, Student Member, IEEE, Mariana Kaiseler, Ana Aguiar, Member, IEEE, \\ João P. Silva Cunha, Senior Member, IEEE, and João Barros, Senior Member, IEEE
}

\begin{abstract}
5 Abstract-The experience of daily stress among bus drivers has 6 shown to affect physical and psychological health, and can im7 pact driving behavior and overall road safety. Although previous 8 research consistently supports these findings, little attention has 9 been dedicated to the design of a stress detection method able 10 to synchronize physiological and psychological stress responses of 11 public bus drivers in their day-to-day routine work. To overcome 12 this limitation, we propose a mobile sensing approach to detect 13 georeferenced stress responses and facilitate memory recall of 14 the stressful situations. Data were collected among public bus 15 drivers in the city of Porto, Portugal $(145 \mathrm{~h}, 36$ bus drivers, $16+2300 \mathbf{~ k m}$ ), and results supported the validation of our approach 17 among this population and allowed us to determine specific stres18 sor categories within certain areas of the city. Furthermore, data 19 collected throughout the city allowed us to produce a citywide 20 "stress map" that can be used for spotting areas in need of local 21 authority intervention. The enriching findings suggest that our 22 system can be a promising tool to support applied occupational 23 health interventions for public bus drivers and guide authorities' 24 interventions to improve these aspects in "future" cities.
\end{abstract}

25 Index Terms-Public transportation, driver, stress detection, 26 wearable technologies, georeferenced data analysis.

\section{INTRODUCTION}

28 RIVER behavior constitutes a major concern in road 30 safety research and policy. Since buses are one of the most 31 used modes of public transportation worldwide, the behavior

Manuscript received May 15, 2014; revised September 21, 2014 and February 19, 2015; accepted May 29, 2015. This work was supported in part by Instituto de Telecomunicações through the R\&D Unit UID/EEA/50008/2013; by Fundo Europeu de Desenvolvimento Regional (FEDER) through Programa Operacional do Norte (ON2); by the applicable financial framework FCT/MEC (PIDDAC) through national funds, within projects VOCE PTDC/EEAELC/121018/2010, FCOMP-01-0124-FEDER-037281, I-CITY Project-ICT for Future Mobility NORTE-07-0124-FEDER-000064, and PTDC/EEIELC/2760/2012 and grants SFRH/BD/62537/2009 and SFRH/BI/51845/2012; and by the European FP7 Project-Future Cities: FP7-REGPOT-2012-2013-1. The Associate Editor for this paper was A. Amditis.

J. G. P. Rodrigues, A. Aguiar, and J. Barros are with the Instituto de Telecomunicações, Departamento de Engenharia Eletrotécnica e de Computadores, Faculdade de Engenharia da Universidade do Porto, 4200-465 Porto, Portugal.

M. Kaiseler is with the Institute for Sport, Physical Activity and Leisure, Leeds Beckett University, Leeds LS1 3HE, U.K., and also with the Instituto de Telecomunicações, Departamento de Engenharia Eletrotécnica e de Computadores, Faculdade de Engenharia da Universidade do Porto, 4200-465 Porto, Portugal.

J. P. S. Cunha is with the Instituto de Engenharia de Sistemas e Computadores-Tecnologia e Ciencia (INESC TEC), Departamento de Engenharia Eletrotécnica e de Computadores, Faculdade de Engenharia da Universidade do Porto, 4200-465 Porto, Portugal.

Color versions of one or more of the figures in this paper are available online at http://ieeexplore.iee.. org

Digital Object Identifier 10.1109/TITS.2015.2445314 of bus drivers and their occupational health becomes a critical 32 priority in overall road safety [1].

Epidemiological evidence from several studies conducted 34 mainly in North America and in Western Europe showed that 35 urban bus drivers have substantially higher mortality rates and 36 higher risk to develop physical and psychological diseases in 37 comparison to many other occupational groups [2]. In agree- 38 ment with this findings, a meta-analysis by Tse et al. [1] 39 reviewing fifty years of research in the area of bus driver 40 well-being concluded that this population is exposed to several 41 sources of stress over time. These can be distinguished in 42 three main categories: physical environment, job design and 43 organizational issues. Physical environment includes sources 44 of stress related with cabin ergonomics, exposure to noise, 45 weather conditions, threat of physical violence, and traffic con- 46 gestion aspects. Job design includes responsibility for security 47 and schedule obedience, working in shifts, long periods of 48 social isolation, ticket selling and control. Organizational issues 49 are related to bus drivers low autonomy and limited decision- 50 making authority. Finally, bus drivers profession is associated 51 with high sedentarism levels, which is known to be a major 52 cause for cardiovascular diseases [3].

The task of driving involves considerable strain for bus 54 drivers, ranging from the needed awareness to safeguard pas- 55 sengers, to traffic hazards [4]. The diversity of daily demands 56 faced by this population causes detrimental effects to their 57 physical and psychological health and well-being, as supported 58 by studies conducted in the occupational [5], ergonomic [6] and 59 biomedical areas [7]. Furthermore, it can also increase the risk 60 of accidents, decreasing overall road safety [1]. Also, stress 61 caused by emotional upsets has been associated with several 62 incidents among drivers [8]. This is probably explained by the 63 fact that emotional states of anger and frustration can increase 64 driver distraction and impair driving performance [9]. Addition- 65 ally, bus drivers role is often conceptualized as high in demands 66 (i.e., traffic congestion, rotating shift patterns, negative passen- 67 ger interaction, tight running times, workload demands, etc.) 68 and low in control with respect to limited decision latitude [6]. 69 This is a main cause for psychological problems [2] and cardio- 70 vascular diseases [10].

In agreement with this idea, an investigation by Baevskii et al. 72 [7] aiming to study the use of principles of prenosological 73 diagnosis for assessing the functional state of the body, has 74 found that bus drivers experienced chronic occupational stress 75 leading to exhaustion of regulatory mechanisms and to rapid 76 development of cardiovascular pathology. As explained by the 77 authors, long-term mental and psychoemotional tension in bus 78 
79 drivers was associated with occupational stress, and leads to 80 the worsening of psychophysiological and cardiorespiratory 81 function of the body. The degree of stress was assessed in this 82 study based on analysis of Heart Rate Variability (HRV).

83 While there is no definitive method of directly assessing 84 physiological stress levels, many techniques have been iden85 tified in the literature, such as heart rate and HRV metrics, 86 electrodermal activity, respiration rate, electromyography and 87 blood volume pressure [11]-[14]. Their results suggest that 88 stress events do indeed cause a reaction perceivable in physio89 logical signals, and that using multiple physiological inputs and 90 incorporating driving event information can greatly increase 91 drivers' stress detection accuracy [15], [16].

92 Although, one can question the ecological validity and re93 liability of driver stress measures collected in laboratory con94 ditions [17]. In opposition, stress assessment research among 95 drivers should take place in ecological settings including non96 intrusive physiologic stress monitoring. Recent advances in 97 noninvasive measurement techniques allowed the progression 98 of human developmental stress research [18], including ambu99 latory monitoring of cardiovascular function [19]-[21]. HRV 100 can be calculated from the Electrocardiogram (ECG), and is 101 reported to be an accurate measure of stress [13]. Recent studies 102 were able to correlate stress with some non-linear HRV features 103 [22], while time-domain and frequency-domain features ex104 tracted from HRV have been validated multiple times as stress 105 indicators in the last decades [13], [14], [23].

106 Nevertheless, stress assessment in ecological settings among 107 bus drivers is not always an easy task, mainly due to difficulties 108 faced when aiming to collect their physiologic and psychologi109 cal stress responses during operation of public vehicles in urban 110 centers [24]. Previous research in this area [25], [26] associ111 ated physiologic (e.g., blood pressure levels, pulse, and urine 112 samples) and psychologic (e.g., self-report and/or researchers 113 observation) measures of stress, and data was collected during 114 bus drivers rest periods. Although these studies provided a 115 crucial contribution to the understanding of daily stress among 116 bus drivers, they are plagued by limitations highlighted below. 117 Primarily, physiologic measures used do not include HRV, 118 considered to be one of the most viable physiologic assessments 119 of stress [14], [23]. Secondly, these research designs failed to 120 understand the physiologic and psychologic impact of a specific 121 source of stress on the driver [27]. Thirdly, the retrospective 122 self-report assessments of sources of stress at the end of a 123 working day may be plagued by attention and memory bias, 124 limiting the driver ability to recall acute stressful events [28]. 125 It is well known that the experience of stress affects quality 126 of memory recall [29]. Furthermore, bus drivers deal with 127 numerous tasks and challenges throughout a day at work (e.g., 128 driving, interaction with passengers and other drivers). Hence, 129 previous research has shown significant discrepancies between 130 real-time assessments and retrospective recall [30], questioning 131 how accurate and valid are results that rely merely on bus 132 drivers memory construction and retrieval.

133 Towards this goal, the current paper proposes an interdis134 ciplinary method that combines physiologic, psychologic and 135 georeferenced data to investigate sources of stress faced by bus 136 drivers while driving in an ecological setting on a daily work basis. Our contribution includes the design of stress assessment 137 software, adapted to the routine needs of bus drivers, and com- 138 bines non-intrusive, user friendly and reliable physiologic and 139 psychologic research methods, providing a continuous daily 140 monitoring of the driver during the course of a day at work. To 141 overcome previous retrospective self-report assessments among 142 bus drivers, our methodology provides a digital contextualiza- 143 tion of potential sources of stress, including environmental cues 144 to trigger memory retrieval [31]. Furthermore, this information 145 is synchronized with the physiologic response for each stressor 146 and the georeferenced location.

Hence, findings will benefit future evaluation of stress 148 sources among bus drivers and will foster the design of efficient 149 occupational health and local road safety interventions.

\section{Methodology}

In this section we describe the technology and methodology 152 that was iteratively improved by real-world experiments with 153 professional bus drivers in the city of Porto, Portugal.

\section{A. Sensing Platform}

Our project targeted a large population, and thus our plat- 156 form was designed to be very easy to use and have very low 157 intrusiveness. These were critical for the wide acceptance and 158 participation we achieved, with 36 volunteers out of 37 drivers 159 introduced to the project.

1) Physiologic Sensors: One kit of equipment was pro- 161 vided to each bus driver, including a VitalJacket, ${ }^{1}$ disposable 162 electrodes, a Global Positioning System (GPS) receiver and a 163 netbook PC. The Vital Jacket (VJ) is a wearable bio-monitoring 164 platform in the form of a $\mathrm{t}$-shirt that provides real time 165 electrocardiogram (ECG) with $500 \mathrm{~Hz}$ sampling rate, 3 axis 166 accelerometer and an event push-button [21], [32]. This data 167 is transmitted to the netbook via Bluetooth from a small box 168 embedded in an easily accessible pocket on the t-shirt.

2) Self-Report Measures: Health and demographic question- 170 naires were completed by participants. This data was used 171 to analyze the impact that demographic metrics have on the 172 drivers' physiologic response (Section IV-C).

Furthermore, bus drivers provided a description of each 174 potential stressor, followed by a stress intensity rating, based 175 on their appraisal of the particular situation. Potential stressful 176 situations were either detected by the system or tagged by the 177 drivers using the push-button incorporated in the VJ. Stress 178 intensity was assessed using a "stress thermometer" where the 179 participant dissected a $10 \mathrm{~cm}$ bipolar line anchored by two 180 statements ("not at all stressful" vs. "extremely stressful"). 181 The "stress thermometer" has demonstrated normal distribution 182 properties and adequate variability in previous stress assess- 183 ment research [33], [34].

3) System Architecture: The GPS receiver used was placed 185 near a bus window and transmits information to the netbook 186 via Bluetooth. A small and lightweight netbook, chosen for its 187

\footnotetext{
${ }^{1}$ BioDevices S.A., www.vitaljacket.com.
} 


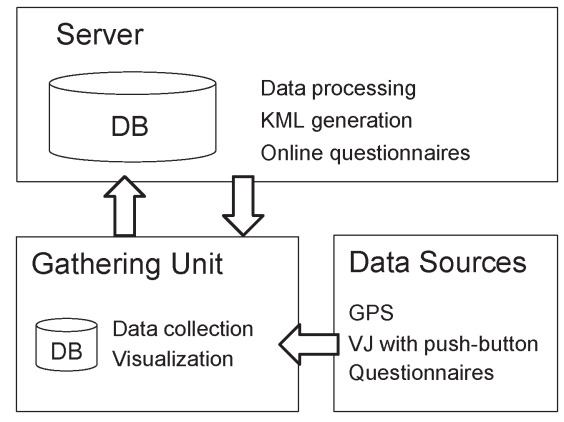

Fig. 1. Hardware architecture.

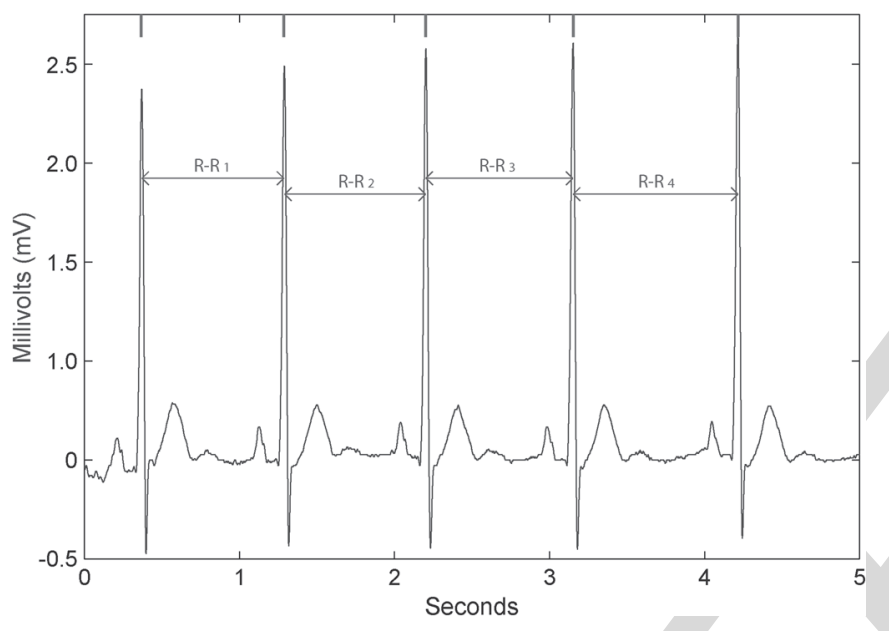

Fig. 2. Sample ECG signal collected from a bus driver and R-R measures.

188 portability, served as the gathering unit. Data processing was 189 performed on a cloud server to increase processing speed. The 190 netbook was used further for visualization in the recall phase 191 (see Section II-B), and the required Internet connectivity was 192 provided by a $3 \mathrm{G}$ network adapter.

193 The architecture of the system designed and implemented 194 to integrate the previous materials is shown in Fig. 1. This 195 architecture and gathering capabilities, such as sensor-data syn196 chronization, reliability and communications have been tested 197 and validated in previous work [35].

198 4) Signal Processing Software: The processing of the ECG 199 signal was performed using the open-source library Phys200 ioToolkit from Physionet [36], which follows the recommen201 dations proposed by the Task Force of The European Society 202 of Cardiology and The North American Society of Pacing and 203 Electrophysiology [13].

204 We used the GQRS tool from the library to extract heartbeat 205 information from the ECG. Fig. 2 shows a 5 second ECG seg206 ment with the $\mathrm{R}$ peaks marked at the top. This tool determines 207 the moment of the peaks for each heartbeat and outputs the 208 inter-beat intervals (R-R) in a format compatible with other 209 Physionet tools.

210 Extra processing and filtering of the cardiac signal was 211 required, as explained in Section III-C, due to the presence of 212 very noisy signals, which can occur in real world research.

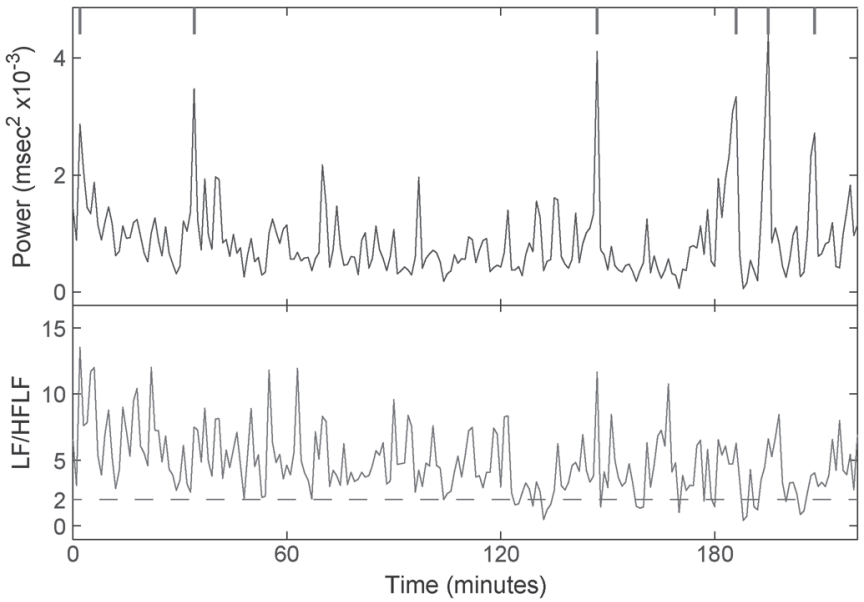

Fig. 3. Low Frequency Power and the ratio between Low Frequency and High Frequency power, for a 3 hour long trip. We use the standardized LF Power to detect stressful events, marked in the top horizontal axis.

We used the HRV Toolkit from Physionet to perform time- 213 domain and frequency-domain analysis of the heart rate in- 214 formation, as suggested by the Task Force of The European 215 Society of Cardiology and The North American Society of 216 Pacing and Electrophysiology [13]. We performed the analysis 217 using a window size of $100 \mathrm{~s}$ with a shift of $60 \mathrm{~s}$ between 218 consecutive windows, and the results were stored for further 219 statistical analysis (which we denominate HRV blocks). We 220 decided to use overlapping windows to improve the time ac- 221 curacy of the results, but we downsample the results when 222 independence between samples is required (see Section III-C). 223 The window size of $100 \mathrm{~s}$ was chosen in order to have a $0.02 \mathrm{~Hz} 224$ of frequency resolution in the frequency-domain results without 225 upsampling. Among others, the metrics include the average 226 normal-to-normal (NN) intervals, the standard deviation of 227 these NN intervals, their low frequency spectral power (LF) 228 between $0.04 \mathrm{~Hz}$ and $0.15 \mathrm{~Hz}$, the high frequency power (HF) 229 between $0.15 \mathrm{~Hz}$ and $0.4 \mathrm{~Hz}$, and the ratio LF/HF.

The spectral power of different frequency bands is specially 231 important to our study, because the power in the HF band is 232 mainly mediated by the parasympathetic system and encom- 233 passes respiratory sinus arrhythmia, but the LF band is medi- 234 ated by both the parasympathetic and sympathetic components, 235 and so they might provide a robust way to assess individual 236 stress [37]. Fig. 3 shows an example of the evolution of the 237 LF power and the LF/HF ratio, which are the two metrics most 238 correlated to stress according to [12] and [23]. The figure shows 239 that spikes are more distinct in the LF than the LF/HF case. A 240 statistical analysis (Section III) confirmed this, leading us to use 241 the LF power as a stress indicator.

5) Detecting Stressful Events: Potentially stressful events 243 were selected from all the moments the driver pushed the button 244 on the VJ, combined with additional 10 blocks with the driver's 245 highest physiologic stress (LF component) but separated at least 246 5 minutes between each other.

6) Enquiry and Visualization Tools: The processed ECG 248 data, together with the GPS information, was used to generate 249 a map at the end of each driver's shift. 


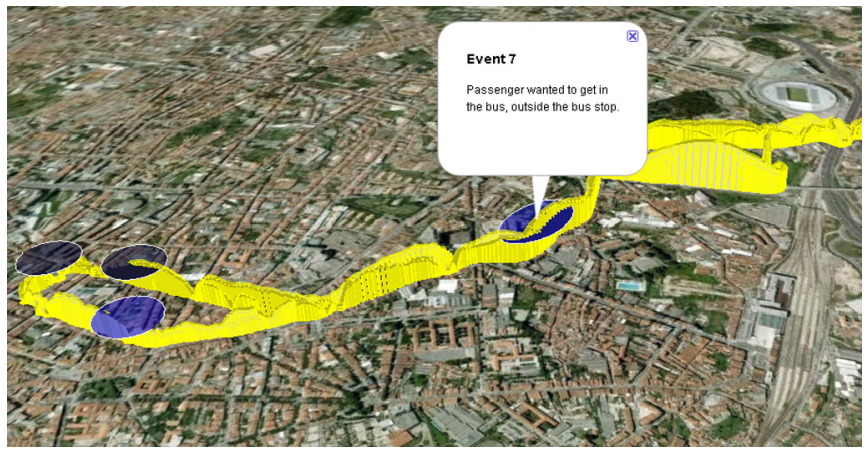

Fig. 4. Visualization of a trip and stress events in Google Earth. The height of the traces represents bus speed, ellipses denotes events.

251 The map was visualized using Google Earth (Fig. 4), pro252 viding a straightforward approach to overlay spatial data and 253 correlate different types of information. Free camera move254 ments and a time toolbar, used to select a time interval window 255 to be displayed, allowed to easily analyze the detected events 256 and their context. To facilitate memory recall, we overlaid 257 information about location and time of the events, as well as the 258 speed of the bus in the whole trip, plotted using a line segment 259 over the map with the height of the line representing speed. 260 By displaying the speed profile for every second of the trip, the 261 driver and researcher could easily identify bus stops and driving 262 events information, such as aggressive braking, accelerations 263 (as in Rigas et al. [16]) and others, aiding them recall and 264 characterize the events. In the map, the detected potentially 265 stressful events were displayed as ellipses spanning over the 266 area traveled during the corresponding 100 s HRV block.

267 The Internet connection from the 3G network adapter was 268 used to access Google Earth and refresh the maps and to 269 synchronize the driver's self-report data to the server. Moreover, 270 the netbook also leveraged this Internet connection to speed up 271 the processing of the ECG signal, sending the raw data to a 272 server that performed all the needed computation and gener273 ated the maps. This upload and cloud processing took around 2744 minutes for a 6 hour work shift. If the computation had been 275 done locally, it would have taken around 15 minutes for the 276 same workload.

\section{B. Procedure}

278 On the day prior to data collection, participants completed 279 a demographic and health questionnaire, and received a kit 280 containing the required equipment. At this time they were given 281 a detailed explanation of the procedures by a researcher. On 282 the data collection day, the bus driver followed the workflow 283 depicted in Fig. 5, wearing the VitalJacket and turning on the 284 netbook and GPS receiver at the beginning of the work shift. 285 Following this procedure, the bus driver was ready to start 286 his work shift, carrying the kit for a full day. The participant 287 was instructed to press the button on the VitalJacket in case of 288 appraising a potentially stressful event during the day, affecting 289 his or the passengers well-being. At the end of the shift, a 290 researcher met the participant at the station, and ran the cloud 291 processing algorithms over the gathered data. A map was then produced displaying the information for the full workday of that 292 participant, as described in Section II-A6.

For each of the displayed ellipses, the driver visualized 294 the exact location and extra information using Google Earth 295 (Fig. 6). For the cases when the participant could remember 296 the event, he was asked to recall that particular situation, and 297 to provide a brief description followed by the stress intensity 298 evaluation for that particular event. The description of the 299 events and stress intensity evaluation were completed in the 300 netbook, but stored and synchronized with the physiologic data 301 on the cloud server.

302

The protocol was designed to obtain the following indepen- 303 dent data sets to help in the detection and categorization of the 304 events:

- Tagged events, providing annotations of on-site self- 307 reported stressors including a description of the situation 308 experienced and stress intensity evaluation;

- Physiologic responses measured with biomedical 310 sensors-HRV blocks;

- Location and velocity information assessed from GPS 312 data, used to detect driving events and facilitate memory 313 retrieval.

- Short annotations for every stressful event detected by the 315 system and confirmed by the driver as stressful, includ- 316 ing a description of the situation experienced and stress 317 intensity evaluation.

This method provided an accurate connection between the 319 georeferenced data, description of the stressor experienced and 320 stress appraisal evaluation for a particular stressor, synchro- 321 nized with physiologic and driving response data. The ellipses 322 provided a general vicinity to the memory retrieval of the event, 323 contextualizing time and location information. Additionally, 324 the method allowed the driver to isolate certain events during 325 the working day by pushing the button. These were saved in the 326 system and available for description and stress intensity evalu- 327 ation later at the end of the work shift.

\section{DATA ANALYSIS}

Thirty-six male professional bus drivers, aged between 29331 and 55 years old $($ Mean $=41$; Standard Deviation $=6.5)$ with 332 experience in bus driving between 3 and 25 years $(M=13 ; 333$ $\mathrm{SD}=6.0$ ), participated in this study. All participants worked 334 for the major transportation company in the city of Porto, 335 Portugal. The exclusion criteria for the study were participants 336 having a history of cardiovascular disease and/or taking pre- 337 scription drugs known to affect cardiovascular function. Partic- 338 ipants volunteering to participate in the study were instructed 339 to perform no changes in their daily routine, such as sport 340 activities and caffeine, nicotine and food consumption.

341

Following approval of the study by the bus company ad- 342 ministration, bus drivers were invited to participate. For this 343 purpose a presentation session was organized by researchers, 344 explaining the aim and protocol of the study. Participants 345 provided informed consent forms prior to participation. 


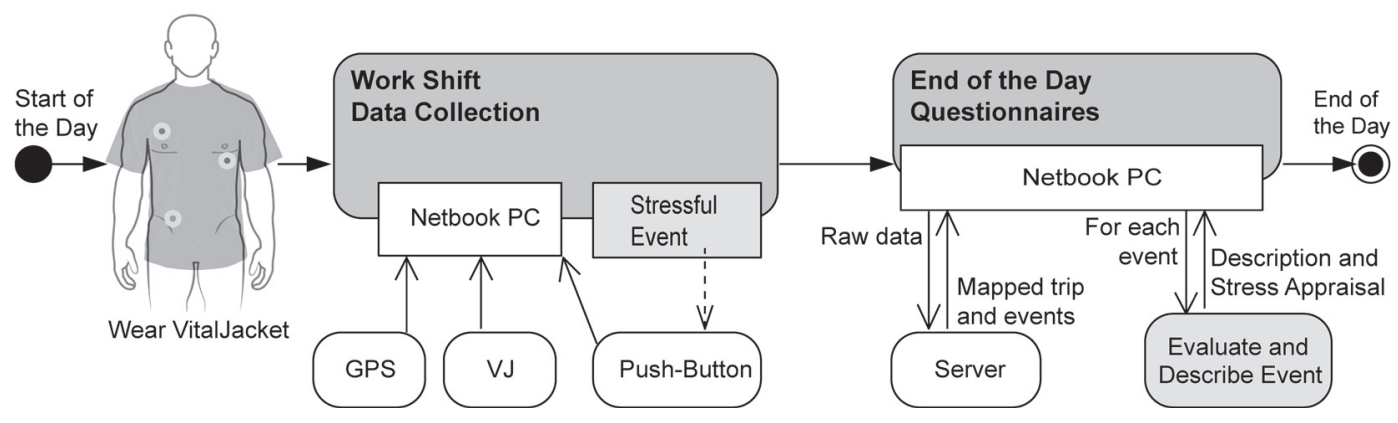

Fig. 5. Workflow on daily data collection.

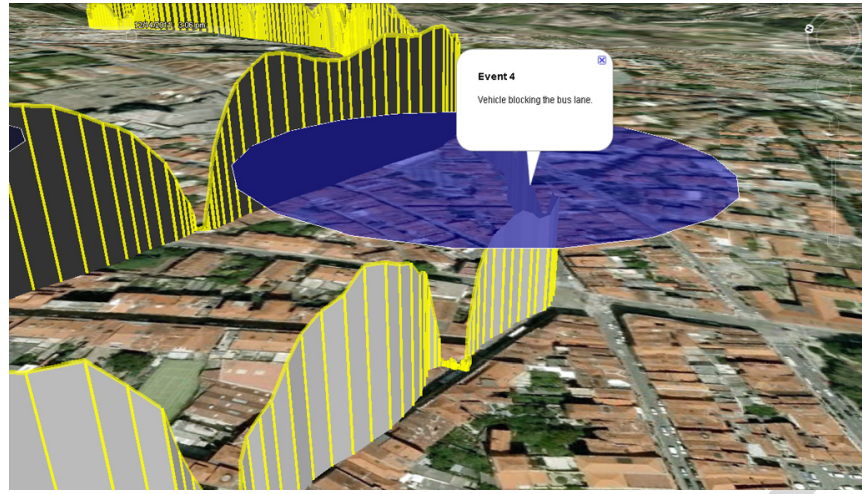

Fig. 6. Close-up of a stress event in Google Earth. The height of the traces represents bus speed.

347 Data was collected for each bus driver over a full working 348 day, corresponding to approximately 5 hours of driving, divided 349 in one or two daytime shifts occurring between $8 \mathrm{AM}$ and $8 \mathrm{PM}$. 350 In total, this study gathered 151 hours of data, including $500 \mathrm{~Hz}$ 351 ECG and location information stored every second that spanned 352 more than $2.500 \mathrm{kms}$.

\section{B. Stressor Categories}

354 Each situation of stress described by the drivers in the 86 355 events was subjected to a content analysis to identify stressors 356 categories. The identified categories are similar to a great extent 357 to the job hassles reported by previous research [27], with a few 358 exceptions discussed in Section V.

359 The first two authors then independently assigned each event 360 into 5 major stressor categories or event types.

361

362 1) Social interactions (e.g., with passengers or friends);

363 2) Unexpected situations (e.g., mechanical failures, driving 364 mistakes, unexpected changes);

365 3) Other drivers or pedestrians behaviors (e.g., other drivers risky behaviors and lack of politeness);

4) Events that impact time schedule (e.g., traffic congestion);

5) Difficult driving due to urban planning (e.g., narrow roads and tight corners).

370 A reliability check showed a level of agreement of $98.8 \%$ be371 tween both researchers after the first categorization. Following 372 some discussion, this agreement increased to $100 \%$.

\section{Filtering and Processing the Physiologic Data}

1) Synchronizing the VJ and GPS Clock: The Physionet 374 library can process the cardiac signal and outputs the metrics 375 we need. However, some extra steps were required in order to 376 synchronize the Physionet output with our GPS data.

We used the GQRS tool from Physionet to detect heart beats, 378 which takes the ECG signal as input with a specified starting 379 time and sample frequency, and outputs the timestamps of 380 every detected beat. Even though the VitalJacket, our ECG 381 sensor, has a fixed $500 \mathrm{~Hz}$ sampling rate, small errors in the 382 VJ clock precision and in the Bluetooth communication can 383 cause discrepancies between the timestamps and duration of 384 the ECG and the GPS data. This clock drift is negligible at 385 the beginning of a trip, since a starting timestamp is given 386 to the application, but naturally increases as the time passes, 387 and sometimes resulted in errors of more than 15 minutes at 388 the end of the $6 \mathrm{~h}$ trips in our pilot experiments. A small 389 desynchronization between the VJ and GPS clocks can cause 390 a huge misplacement of a stressful event, since buses can travel 391 at up to $50 \mathrm{~km} / \mathrm{h}(14 \mathrm{~m} / \mathrm{s})$

To correct this synchronization issue our processing algo- 393 rithm keeps track of the GPS clock and also of a virtual one 394 that follows the beat-detector fixed $1 / 500 \mathrm{~s}$ per data sample. The 395 differences between both clocks is constantly analyzed, and the 396 ECG stream is split and given a new corrected timestamp every 397 time a shift of more than $10 \mathrm{~s}$ is detected.

2) Detecting Noisy ECG Data: Another problem we de- 399 tected in our pilot experiments when processing the data was 400 ECG noise. The heartbeat detectors perform poorly in the 401 presence of very noisy signals that can occur in real world 402 scenarios like ours, leading to the detection of false-positive 403 stressful events. There are many sources of noise in a real world 404 environment, such as from other muscular activity or electrode 405 misplacement, which can significantly reduce the accuracy of 406 the heartbeat detection algorithms.

We implemented a Standard Deviation (SD) filter to detect 408 extremely noisy blocks of data and improve the reliability of 409 the ECG data. This filter calculates the SD of the raw ECG 410 every second (500 samples), discarding an HRV block from 411 the analysis if it contains any second with an SD higher than 412 a threshold. The filter successfully detected the trips belonging 413 to 2 drivers who misplaced the electrode patches, and also other 414 3 trips that presented problems with the electrodes' connection 415 after some point in the middle of the trip. After analyzing these 416 
417 trips, the threshold was set as the 90th percentile of all of our 418 data, eliminating the $10 \%$ noisiest ECG data gathered in our 419 real world scenario. The SD filter was applied to $151 \mathrm{~h}$ of 420 gathered data, resulting in 1470 discarded HRV blocks. From 421 these, 1349 (92\%) belonged to 5 trip segments with problems 422 in the electrode patches.

423 3) Push-Button Time Correction: Another filtering step was 424 the correction of tagged events' timestamps. This consisted in 425 correlating the push-button events with the correct HRV block 426 of physiologic sensor data by analyzing the driver description of 427 the event and surrounding trip data, such as location and speed. 428 Most of the events were associated with the block that imme429 diately preceded it, meaning that the drivers pressed the button 430 right after they experienced a stressful situation. However, in 431 some cases they were associated with the following block, 432 because some drivers pressed the button when approaching a 433 known dangerous place.

434 4) HRV Metrics Standardization: Different drivers have dif435 ferent cardiac characteristics and baselines, preventing us from 436 comparing HRV metrics between multiple drivers. Since we 437 could not collect a baseline for each driver in a relaxed and 438 controlled environment, we decided to standardized the cardiac 439 metrics per driver. To this end, the HRV metrics of each driver's 440 entire collection day were transformed to have zero mean and 441 unit variance.

442 5) Downsampling to Independence: The final step in our 443 processing algorithm was the downsampling of the HRV blocks 444 for each driver in order to increase independence between 445 samples. The recalled events were already selected with at least $4465 \mathrm{~min}$ of data between them. However, the rest of the ECG 447 was analyzed every minute but with a window size of $100 \mathrm{~s}$, 448 resulting in $40 \mathrm{~s}$ overlap between HRV blocks, and producing 449 a dependent dataset of HRV metrics. To make the HRV blocks 450 independent, the processed and filtered blocks were downsam451 pled for each driver, removing the minimum number of blocks 452 that guarantees the same 5 min distance between HRV blocks 453 or any recalled or tagged events.

\section{RESULTS}

455 We gathered a total of 9081 HRV Blocks, from which 1470 456 were filtered as noise and 6050 were removed in the downsam457 pling process. From the 36 drivers, 2 had misplaced electrodes 458 providing no useful ECG data and other 2 forgot to turn on 459 the GPS device. 29 events were tagged on-site as stressful by 46011 drivers. Some drivers forgot they were being monitored and 461 thus forgot to press the button in stressful situations, others were 462 distracted dealing with the situations.

463 To facilitate the events recall, 320 distinct blocks were iden464 tified by the system and shown to the 32 drivers in the map 465 at the end of the day. From these, 57 blocks were recalled as 466 stressful events and evaluated by 27 bus drivers, 2 drivers did 467 not recall any additional events besides the ones they tagged, 468 and 3 stated they did not experience any stressful situations 469 during their work shift.

470 Our final dataset to be analyzed contains stress information 471 from 29 drivers, with 29 on-site tagged events, 57 events

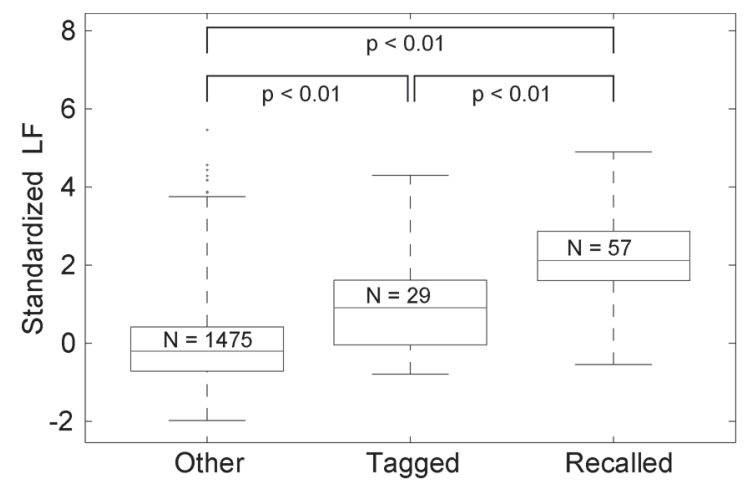

Fig. 7. Distribution of calculated stress between other blocks, tagged events, and events recalled at the end of the day.

recalled at the end of the day, and other $1475 \mathrm{HRV}$ blocks not 472 identified as stressful. Thus, a total of 1561 independent rows 473 of data standardized per driver.

Due to non-normalized distributions of the data, we used 475 non-parametric tests. The Mann-Whitney U-Test [38] was 476 chosen to compare the distributions of two populations, the 477 Kruskal-Wallis Test [39] to verify if more than two popula- 478 tions have the same distributions, and the Kendall's Tau [40] 479 to check for statistical dependence between variables in the 480 same population. To this end, multiple pairwise MannWhitney 481 U-Tests were conducted to analyze differences in the main 482 HRV metrics between the samples classified as tagged events, 483 recalled events and others. Kruskal-Wallis Test was conducted 484 to test for differences in the LF spectral power across stressor 485 categories in both self-reported and cardiac stress responses. 486 Kendall's Tau rank correlation test was used to search for 487 statistical association between demographic and physiologic 488 variables.

\section{A. Physiologic vs Recalled Stress Assessment}

Our system used the LF component of the interbeat intervals 491 as a stress indicator, as proposed by [12] and [23]. To validate 492 this proposition, we compared the LF frequency component of 493 all blocks, the tagged events and the stress events recalled at the 494 end of the day (Fig. 7).

The MannWhitney U-Test showed significant difference be- 496 tween the distributions of LF power for other and tagged events 497 $\left(\mathrm{z}=-4.91, \mathrm{p}=9.16^{-7}\right)$, indicating that there is a significant 498 increase of the LF power during events appraised as stressful 499 by the driver. The recalled events also presented a statistically 500 higher LF component than the tagged events $(\mathrm{z}=-4.85, \mathrm{p}=501$ $\left.1.23^{-6}\right)$, even when analyzing only the 11 drivers who tagged 502 events.

503

The same statistical analysis between tagged and other events 504 was performed for every HRV metric, and some are presented in 505 Table I. The metric that showed the most statistically significant 506 difference was the LF power, followed by the time-domain 507 metrics that detect variability, such as standard deviation of 508 heart beat intervals. 
TABLE I

Distribution Tests' Results BetweEn Other ANd TAgGed EVENTS OF DIFFERENT HRV METRICS FROM THE HRV TOOLKIT

\begin{tabular}{l|c|c|c|c|c|c}
\hline MannWhitney & AVNN & SDNN & pNN50 & LF & HF & LF/HF \\
Z value & -0.68 & -4.19 & -2.75 & -4.91 & -2.39 & -1.42 \\
P value & 0.50 & $<\mathbf{0 . 0 1}$ & $<\mathbf{0 . 0 1}$ & $<\mathbf{0 . 0 1}$ & $\mathbf{0 . 0 2}$ & 0.16 \\
\hline
\end{tabular}

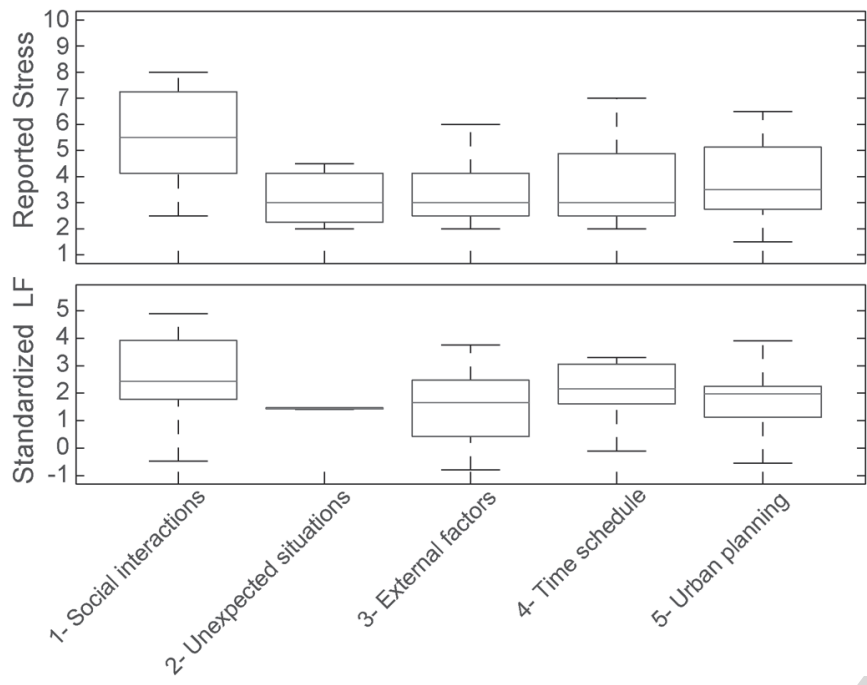

Fig. 8. Distribution of the stress level throughout the different stress categories, for both reported stress evaluated by the stress thermometer, and calculated from the ECG signal.

TABLE II

FREQUENCY ANALYSIS FOR REPORTED STRESSOR CATEGORIES: NUMBER OF REPORTS, FREQUENCY RELATIVE TO THE TOTAL Number of EVENTS, NuMber OF DisTINCT DRIVERS THAT REPORTED THAT CATEGORY, AND CORRESPONDING RELATIVE FREQUENCY TO THE NUMBER OF DRIVERS

\begin{tabular}{l|c|c|c|c|c|c}
\hline Stressor Category & 1 & 2 & 3 & 4 & 5 & Total \\
\hline Total Count & 14 & 7 & 30 & 16 & 19 & 86 \\
Relative Frequency & $16 \%$ & $8 \%$ & $35 \%$ & $19 \%$ & $22 \%$ & \\
Drivers & 11 & 6 & 18 & 12 & 12 & 29 \\
Drivers Frequency & $38 \%$ & $21 \%$ & $62 \%$ & $41 \%$ & $41 \%$ & \\
\hline
\end{tabular}

\section{B. Analysis of Stressor Categories}

511 Fig. 8 shows an overview of the distributions for physiologic 512 and self-reported stress intensity evaluation for each stressor cat513 egory, introduced in Section III-B. An event was only considered 514 to be stressful when appraised by the bus driver as higher than 0 515 in the stress thermometer scale (51 of the 86 identified events). 516 The Kruskal-Wallis Test showed that no significant differ517 ences across stressor categories exist either for self-reported $518 X^{2}(4, N=51)=7.62 ; p=0.11$; or for cardiac stress re519 sponses $X^{2}(4, N=51)=4.82 ; p=0.31$.

520 Table II shows a frequency analysis of stress categories 521 combining all tagged and recalled events appraised as stressful 522 by bus drivers. Other drivers or pedestrians behaviors were the 523 most commonly reported source of stress, reported for 35\% of 524 the recalled or tagged events and mentioned at least once by $52562 \%$ of the 29 bus drivers. Difficulty driving due to urban plan526 ning was the second most reported source of stress, reported for $52722 \%$ of the events recalled or tagged, and mentioned by $41 \%$ of 528 the drivers (12/29). Also, events that impact time schedule was 529 a frequently reported source of stress, accounting for $19 \%$ of 530 the events and mentioned by $41 \%$ of the drivers.
TABLE III

Kendall's TAu TEST Results For Demographic AND Full-DAY CARDiaC METRICS. P VALUES LOWER THAN 0.05 ARE MARKED AS BOOLEAN

\begin{tabular}{|l|cc|cc|cc|}
\hline & \multicolumn{2}{|c|}{ Age } & \multicolumn{2}{c|}{ Weight } & \multicolumn{2}{c|}{ Experience } \\
& Tau & P & Tau & P & Tau & P \\
\hline AvgAVNN & 0.0 & 0.84 & 0.3 & 0.06 & -0.3 & $\mathbf{0 . 0 2}$ \\
AvgSDNN & 0.0 & 0.87 & 0.1 & 0.72 & -0.3 & $\mathbf{0 . 0 1}$ \\
AvgLF & -0.1 & 0.32 & 0.1 & 0.63 & -0.3 & $\mathbf{0 . 0 4}$ \\
AvgHF & -0.2 & 0.09 & 0.1 & 0.45 & -0.3 & $\mathbf{0 . 0 2}$ \\
AvgLF/HF & 0.1 & 0.37 & -0.1 & 0.72 & 0.0 & 0.93 \\
\hline
\end{tabular}

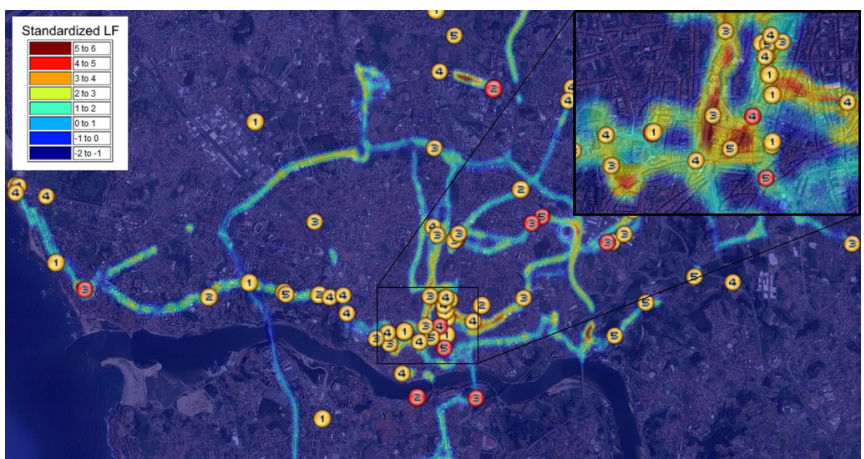

Fig. 9. Stress map of Porto with placemarks on detected stressful events. The numbers represent the event category, the darker marks are tagged events and lighter are events recalled at the end of the day.

\section{Questionnaires and per Driver Analysis}

In this project we also analyzed the questionnaires data 532 and their correlations with the cardiac metrics. We combined 533 the questionnaires answers with the HRV analysis over each 534 driver's full dataset, resulting in metrics such as a driver's 535 age, height, weight, years of experience as a bus driver, usual 536 exercise routine, and also the full day's average heart rate, 537 average spectral power for different frequencies, and others. $\quad 538$

To analyze the data we performed cross-correlation analysis 539 between all variables using Kendall's Tau $(\tau)$ rank correlation 540 test [40]. The main results are presented in Table III, with cor- 541 related variables resulting in a p-value lower than 0.05 marked 542 in bold.

The results show a strong correlation between the cardiac 544 metrics and the years of experience of the drivers, and not with 545 any other demographic metric.

\section{Geo-Referenced Stress Analysis}

Furthermore, the analysis of the tagged and recalled stress 548 events showed that more than $75 \%(65 / 86)$ of the stressors are 549 location-dependent, such as tight roads, low-visibility cross- 550 walks and drivers not respecting signalization on some cross- 551 roads. This data suggests that the geographic reference of 552 detected events provided by our method was efficient in facili- 553 tating bus drivers' memory retrieval, and also that it is possible 554 to provide valuable stress-maps to decision makers. With both 555 physiologic and psychologic stress assessment performed with 556 our methodology, we are able to map their intensity and detect 557 systematically stressful locations.

Fig. 9 shows a stress map of the city of Porto, where lighter 559 areas represents less stressful and darker areas represents highly 560 
561 stressful places. Also, darker symbols mark the spots where 562 stressful events were tagged, lighter ones were recalled at 563 the end of the day, and the numbers correspond to the event 564 category as stated in Section III-B. The map was generated by 565 clustering and averaging the Standardized LF information of 566 the HRV blocks. Additionally, in order to eliminate biases in the 567 cardiac data associated with physical activity, we discarded data 568 gathered while the bus was almost stopped (less than $5 \mathrm{~km} / \mathrm{h}$ ) 569 and only map clusters with data from at least 3 distinct drivers. 570 Based on Fig. 9 it is clear that the city downtown, near 571 the center of the map, is a stressful region with many highly572 stressful roads being detected in that dense urban zone. How573 ever we can also find other less obvious highly-stressful zones, 574 such as in the left-middle edge of the map, where a roundabout 575 caused a cardiac response in all of the 4 drivers that passed by 576 and even a tagged event from one of the drivers.

\section{DiscusSiON}

578 The aim of the current paper was to investigate daily sources 579 of stress faced by bus drivers while driving in an ecologi580 cal setting during their daily work. Results suggest that the 581 proposed method is accurate in detecting psychological and 582 physiological stress responses. Despite the divergence in the 583 concept definition and assessment of stress, our findings are 584 consistent with previous research recommendations [41].

585 Particularly, results showed a significant increase of the LF 586 component of HRV during events appraised as stressful by the 587 driver, suggesting that the stress concept assessment can com588 bine both psychologic and physiologic dimensions of stress, 589 while also contemplating an integrative approach in the real 590 world. Contrary to the results presented by McCraty et al. [12] 591 and Healey and Picard [23], the LF/HF does not show a statisti592 cally different distribution between tagged stressful events and 593 other HRV blocks, which may be due to the higher HF noise 594 present in real word scenarios like the one in this study. This 595 indicates that the LF power is the best stress metric for our 596 scenario.

597 Regarding demographic factors and their impact on the 598 drivers' physiologic response, results indicate that years of 599 experience of the driver is an important factor to consider. 600 Surprisingly, even the age, which is correlated with the years 601 of experience, is not significantly correlated with the physio602 logic metrics. This suggests that, although cardiac response is 603 known to decrease with age [42], more experienced drivers (not 604 necessarily older ones) have less cardiac response to stressful 605 events and a smoother physiologic response throughout the 606 entire working day. Further research is required controlling for 607 bus drivers routes in order to confirm whether this finding is 608 due to effective coping strategies developed by this population 609 or the experience of different environmental demands.

610 In what concerns to sources of stress found in our study 611 (Section III-B), these are similar to a great extent to the job 612 hassles reported by Johansson et al. [27] among bus drivers 613 working in the city of Stockholm (e.g., traffic congestion, illegal 614 parking of vehicles, risky or impolite behaviors of other divers 615 or pedestrians, mechanical difficulties, timetable restrictions). 616 However, in the current study, social interactions with passen- gers or friends and bus driving mistakes were also reported 617 as stressors in $16 \%$ of the reported events and by $38 \%$ of the 618 drivers $(11 / 29)$. We believed that this fact may be mainly related 619 to the methods used in this study that facilitated the drivers 620 memory retrieval of events. On the other hand, previous re- 621 search methods used across studies relied on retrospective self- 622 reports following long periods of time what may had affected 623 the type of stressors reported. Additionally, other previous 624 studies were based on the researcher observations, whereas 625 our study relied on a more ecological setup and based on the 626 inputs of the drivers themselves, i.e. their own perceptions 627 and experiences of stress. As a result, stress categories such 628 as the experiences of interpersonal stressors are unlikely to 629 be reported by others, who merely described what they can 630 observe. Also, the constant presence of an observer may pro- 631 duce biased results, making the driver less likely to do driving 632 mistakes and avoid communicating with friends entering the 633 bus. Hence, we believe that the type of stress categories found 634 in this study complements the literature in the area and reinforce 635 the strengths of the methodology used to capture drivers acute 636 stressors experienced on a daily basis.

It is important to highlight that the current ecological method 638 culminates a previous limitation in the area of stress reactivity 639 assessment [43], and provides a crucial contribution to the study 640 of cardiovascular reactivity to stress in real world scenarios. 641 This is a fundamental relationship when investigating sources 642 of stress, critical to the etiology of cardiovascular disease [27]. 643 Furthermore, as suggested by Myin-Germeys et al. [44] stress 644 responses assessed in real life situations are more likely to be 645 closer to reality than those collected under laboratory settings. 646

Additionally, the inclusion of georeferenced information and 647 its visualization by bus drivers was a key aspect in this method- 648 ology, facilitating memory retrieval of the experienced situa- 649 tions, thus providing a detailed description and specificity of 650 stressors. To support this argument the proposed methodology 651 allowed the collection of 57 additional stressors in the city of 652 Porto, compared with only 29 voluntarily tagged by bus drivers. 653

In sum, the proposed methodology provides detailed infor- 654 mation of different stressors experienced by bus drivers, and 655 their specific location in a city. It is believed that this informa- 656 tion can induce evidence based decisions across a variety of 657 areas (e.g., ergonomics, security, management, technological, 658 public policy, psychologic and urban planning). Additionally, 659 the system is able to map exactly where in the city these events 660 have occurred and the average stress intensity for the sensed 661 areas, what is likely to result in more efficient decision making. 662 Furthermore, the mapped placemarks are clickable on Google 663 Earth, allowing decision makers to see detailed information of 664 each stress event, such as intensity and description.

\section{CONCLUSION}

We proposed an interdisciplinary methodology for assess- 667 ing sources of stress in professional bus drivers based on 668 the population's real world needs. The system was designed 669 by an interdisciplinary team, in cooperation with bus drivers 670 working in the city of Porto. The method validation was tested 671 among a sample of bus drivers in their day-to-day routine. 672 
673 Results showed that the methodology is successful in detecting 674 stressful events based on bus drivers' physiologic responses. 675 Furthermore, the system provides real world visual cues and 676 information, which seems to facilitate driver memory retrieval, 677 enriching description of stressful events, and findings provide 678 contextualized sources of stress within a city. Applied impli679 cations of this method will foster evidence based solutions at 680 enterprise, policy-makers and government levels, providing an 681 open approach to improvement and change towards developing 682 bus drivers' occupational health, improving driver performance, 683 and enhancing overall road safety. Theoretical implications of 684 this paper also include contributions to the stress assessment 685 literature in general and particularly to the occupational health. 686 Findings provide strong theoretical and practical implica687 tions. Respectively, the method makes a valuable contribution 688 to the occupational health stress assessment literature. Ad689 ditionally, practical implications will facilitate the design of 690 holistic occupational health interventions for bus drivers while 691 also guiding authorities interventions aiming to increase road 692 safety. Current ongoing work is deploying this methodology 693 over a larger population in order to perform a comprehensive 694 characterization of sources of stress among professional bus 695 drivers in the city of Porto.

\section{ACKNOWLEDGMENT}

697 We would like to thank Sociedade de Transportes Colectivos 698 do Porto STCP for collaborating in this study, and to Susana 699 Brís, Ph.D., from IEETA/University of Aveiro for her insights 700 in ECG filtering techniques.

\section{REFERENCES}

1] J. L. Tse, R. Flin, and K. Mearns, "Bus driver well-being review: 50 years of research," Transp. Res. Part F Traffic Psychol. Behav., vol. 9, no. 2, pp. 89-114, Mar. 2006.

[2] G. W. Evans and S. Carrère, "Traffic congestion, perceived control, and psychophysiological stress among urban bus drivers," J. Appl. Psychol., vol. 76, no. 5, pp. 658-663, Oct. 1991.

3] K. E. Powell, P. D. Thompson, C. J. Caspersen, and J. S. Kendrick, "Physical activity and the incidence of coronary heart disease," Annu. Rev. Public Health, vol. 8, pp. 253-287, May 1987.

[4] M. S. Joshi, V. Senior, and G. P. Smith, "A diary study of the risk perceptions of road users," Health. Risk Soc., vol. 3, no. 3, pp. 261-279, Nov. 2001.

[5] M.-J. Chen and C. Cunradi, "Job stress, burnout and substance use among urban transit operators: The potential mediating role of coping behaviour," Work Stress, vol. 22, no. 4, pp. 327-340, Oct. 2008.

[6] N. J. Ward et al., "An evaluation of a lane support system for bus rapid transit on narrow shoulders and the relation to bus driver mental workload," Ergonomics, vol. 49, no. 9, pp. 832-859, Jul. 2006.

[7] R. M. Baevskii, A. P. Berseneva, E. Y. Bersenev, and A. K. Eshmanova, "Use of principles of prenosological diagnosis for assessing the functional state of the body under stress conditions as exemplified by bus drivers," Human Physiol., vol. 35, no. 1, pp. 34-42, Jan. 2009.

[8] R. D. Blasco, J. M. Prieto, and J. M. Cornejo, "Accident probability after accident occurrence," Safety Sci., vol. 41, no. 6, pp. 481-501, Jul. 2003.

[9] A. N. Stephens and J. A. Groeger, "Do emotional appraisals of traffic situations influence driver behaviour?" Behav. Res. Road Safety, pp. 49-62, 2006.

10] M. A. J. Kompier and V. Di Martino, "Review of bus drivers' occupational stress and stress prevention," Stress Med., vol. 11, no. 1, pp. 253-262, Jan. 1995.

11] T. G. M. Vrijkotte, L. J. P. van Doornen, and E. J. C. de Geus, "Effects of work stress on ambulatory blood pressure, heart rate, and heart rate variability," Hypertension, vol. 35, no. 4, pp. 880-886, Apr. 2000.
[12] R. McCraty, M. Atkinson, W. A. Tiller, G. Rein, and A. D. Watkins, 735 "The effects of emotions on short-term power spectrum analysis of 736 heart rate variability," Amer. J. Cardiol., vol. 76, no. 14, pp. 1089-1093, 737 Nov. 1995.

[13] Task Force of The European Society of Cardiology and The North 739 American Society of Pacing and Electrophysiology, "Heart rate variabil- 740 ity: Standards of measurement, physiological interpretation, and clinical 741 use," Eur. Heart J., vol. 17, pp. 354-381, 1996.

[14] J. Choi, B. Ahmed, and R. Gutierrez-Osuna, "Development and evaluation 743 of an ambulatory stress monitor based on wearable sensors," IEEE Trans. 744 Inf. Technol. Biomed., vol. 16, no. 2, pp. 279-286, Mar. 2012.

[15] P. Besson et al., "Effectiveness of physiological and psychological fea- 746 tures to estimate helicopter pilots' workload: A bayesian network ap- 747 proach," IEEE Trans. Intell. Transp. Syst., vol. 14, no. 4, pp. 1872-1881, 748 Dec. 2013.

[16] G. Rigas, Y. Goletsis, and D. I. Fotiadis, "Real-time driver's stress event 750 detection," IEEE Trans. Intell. Transp. Syst., vol. 13, no. 1, pp. 221-234, 751 Mar. 2012.

[17] F. H. Wilhelm and P. Grossman, "Emotions beyond the laboratory: The- 753 oretical fundaments, study design, and analytic strategies for advanced 754 ambulatory assessment," Biol. Psychol., vol. 84, no. 3, pp. 552-569, 755 Jul. 2010.

[18] M. Gunnar and K. Quevedo, "The neurobiology of stress and develop- 757 ment," Annu. Rev. Psychol., vol. 58, pp. 145-173, Jan. 2007.

[19] S. M. Collins, "Emerging methods for the physiological assessment of 759 occupational stress," Work, vol. 17, no. 3, pp. 209-219, Jan. 2001.

[20] S. Shiffman, A. A. Stone, and M. R. Hufford, "Ecological momen- 761 tary assessment," Annu. Rev. Clin. Psychol., vol. 4, no. 1, pp. 1-32, 762 Apr. 2008.

[21] J. Cunha et al., "Vital-Jacket: A wearable wireless vital signs monitor for 764 patients' mobility in cardiology and sports," in Proc. Int. Conf. Pervasive- 765 Health, Mar. 2010, pp. 1-2.

[22] P. Melillo, M. Bracale, and L. Pecchia, "Nonlinear Heart Rate Variability 767 features for real-life stress detection. Case study: Students under stress 768 due to university examination," Biomed. Eng. Online, vol. 10, no. 1, p. 96, 769 Nov. 2011.

[23] J. A. Healey and R. W. Picard, "Detecting stress during real-world driv- 771 ing tasks using physiological sensors," IEEE Trans. Intell. Transp. Syst., 772 vol. 6, no. 2, pp. 156-166, Jun. 2005. 773

[24] G. W. Evans, G. Johansson, and L. Rydstedt, "Hassles on the job: A study 774 of a job intervention with urban bus drivers," J. Org. Behav., vol. 20, 775 no. 2, pp. 199-208, Mar. 1999.

[25] B. Netterstrom and A. M. Hansen, "Outsourcing and stress: physiolog- 777 ical effects on bus drivers," Stress Med., vol. 16, no. 3, pp. 149-160, 778 Apr. 2000.

[26] L. W. Rydstedt, G. Johansson, and G. W. Evans, "The human side of the 780 road: Improving the working conditions of urban bus drivers," J. Occup. 781 Health Psychol., vol. 3, no. 2, pp. 161-171, Apr. 1998.

[27] G. Johansson, G. W. Evans, L. W. Rydstedt, and S. Carrere, "Job hassles 783 and cardiovascular reaction patterns among urban bus drivers," Int. J. 784 Behav. Med., vol. 5, no. 4, pp. 267-280, Jan. 1998.

[28] S. C. Segerstrom and D. B. O'Connor, "Stress, health and illness: Four 786 challenges for the future," Psychol. Health, vol. 27, no. 2, pp. 128-140, 787 2012.

[29] L. Schwabe et al., "Stress modulates the use of spatial versus stimulus- 789 response learning strategies in humans," Learn. Mem., vol. 14, no. 1, 790 pp. 109-116, Jan./Feb. 2007.

[30] M. R. Hufford, S. Shiffman, J. Paty, and A. A. Stone, "Ecological 792 momentary assessment: Real-world, real-time measurement of patient 793 experience," in Progress in Ambulatory Assessment: Computer-Assisted 794 Psychological and Psychophysiological Methods in Monitoring and Field 795 Studies. Kirkland, WA, USA: Hogrefe \& Huber Publishers, 2001, 796 pp. 69-92.

[31] I. R. Olson and C. Marshuetz, "Remembering 'what' brings along 798 'where' in visual working memory," Perception Psychophys., vol. 67, 799 no. 2, pp. 185-194, Feb. 2005.

[32] J. P. S. Cunha, "PHealth and wearable technologies: A permanent chal- 801 lenge," Stud. Health Technol. Inform., vol. 177, pp. 185-195, 2012.

[33] K. C. Kowalski and P. R. E. Crocker, "Development and validation of the 803 Coping Function Questionnaire for adolescents in sport," J. Sport Exercise 804 Psychol., vol. 23, no. 2, pp. 136-155, Jun. 2001.

[34] M. Kaiseler, R. Polman, and A. Nicholls, "Mental toughness, stress, stress 806 appraisal, coping and coping effectiveness in sport," Pers. Individual 807 Difference, vol. 47, no. 7, pp. 728-733, Nov. 2009.

[35] J. G. P. Rodrigues, A. Aguiar, F. Vieira, J. Barros, and J. P. S. Cunha, 809 "A mobile sensing architecture for massive urban scanning," in Proc. 810 IEEE ITSC, Oct. 2011, pp. 1132-1137. 
812 [36] A. L. Goldberger et al., "PhysioBank, PhysioToolkit, and PhysioNet: 813 Components of a new research resource for complex physiologic signals," 814 Circulation, vol. 101, no. 23, pp. e215-e220, Jun. 2000.

815 [37] S. Akselrod et al., "Power spectrum analysis of heart rate fluctuation: 816 A quantitative probe of beat-to-beat cardiovascular control," Science, 817 vol. 213, no. 4504, pp. 220-222, Jul. 1981.

818 [38] H. B. Mann and D. R. Whitney, "On a test of whether one of two ran819 dom variables is stochastically larger than the other," Ann. Math. Statist., 820 vol. 18, no. 1, pp. 50-60, Mar. 1947.

821 [39] W. H. Kruskal and W. A. Wallis, "Use of ranks in one-criterion vari822 ance analysis," J. Amer. Statist. Assoc., vol. 47, no. 260, pp. 583-621, 823 Dec. 1952.

824 [40] M. G. Kendall, "A new measure of rank correlation," Biometrika, vol. 30, 825 no. $1 / 2$, pp. 81-93, Jun. 1938.

826 [41] D. S. Goldstein and I. J. Kopin, "Evolution of concepts of stress," Stress, 827 vol. 10, no. 2, pp. 109-120, Jun. 2007

828 [42] K. Umetani, D. H. Singer, R. McCraty, and M. Atkinson, "Twenty-four 829 hour time domain heart rate variability and heart rate: Relations to age 830 and gender over nine decades," J. Amer. College Cardiol., vol. 31, no. 3, 831 pp. 593-601, Mar. 1998.

832 [43] Y. J. Zanstra and D. W. Johnston, "Cardiovascular reactivity in real 833 life settings: Measurement, mechanisms and meaning," Biol. Psychol., 834 vol. 86, no. 2, pp. 98-105, Feb. 2011.

835 [44] I. Myin-Germeys et al., "Experience sampling research in psychopathol836 ogy: Opening the black box of daily life," Psychol. Med., vol. 39, no. 9, 837 pp. 1533-1547, Sep. 2009.

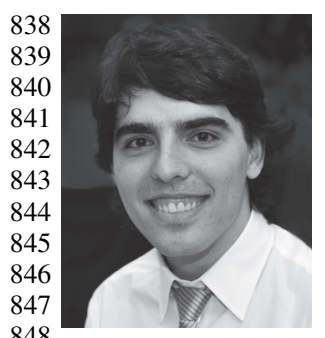

João G. P. Rodrigues (S'11) received the M.Sc. degree in electrical and computer engineering from the University of Porto, Porto, Portugal, in 2009. He is currently working toward the Ph.D. degree with the University of Porto. He develops his work at the Institute for Telecommunications, and the main topics of his thesis are data gathering and mining in intelligent transportation systems. His main research interests include sensor networks and intelligent transportation systems. He received a Doctoral 849 ence and Technology in 2009. cholarship from the Portuguese Foundation for $\mathrm{Sci}-$

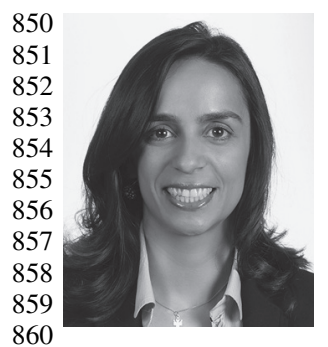

Mariana Kaiseler received the M.Sc. degree in sport science and the Ph.D. degree in sport psychology from the University of Hull, Hull, U.K., and the Postgraduate Certificate in Teaching and Learning in Higher Education from the University of Derby. She is currently a Senior Lecturer in Sports and Exercise Psychology at Carnegie Faculty. She is also an Expert Evaluator for the European Commission and acts as a Peer Reviewer for several prestigious journals in her field. Her research interests include the study of stress, coping, and emotions in sport 861 and occupational health settings. She received funding from a number of 862 universities and external funding bodies, and was awarded the first Marie Curie 863 Fellowship at the Faculty of Psychology, University of Porto, Portugal. She is 864 a Chartered member and Associate Fellow of the British Psychological Society 865 and a Fellow of the Higher Education Academy.

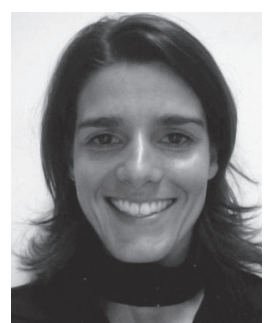

Ana Aguiar (S'94-M'98-S'02-M'09) received the 866 Electrical and Computer Engineering degree from 867 the University of Porto, Porto, Portugal, in 1998, and 868 the $\mathrm{Ph} . \mathrm{D}$. in telecommunication networks from the 869 Technical University of Berlin, Berlin, Germany, in 870 2008. Since 2009, she has been an Assistant Pro- 871 fessor with the Faculty of Engineering, University 872 of Porto. She began her career as an RF Engineer 873 working for cellular operators, and she worked at 874 Fraunhofer Portugal AICOS on service-oriented ar- 875 chitectures and wireless technologies applied to am- 876 bient assisted living. She is the author of several papers published and presented 877 in IEEE and ACM journals and conferences, respectively. She contributes to 878 several interdisciplinary projects in the fields of intelligent transportation sys- 879 tems and well being (stress). Her research interests include wireless networking 880 and mobile sensing systems, specifically vehicular networks, crowd sensing, 881 and machine-to-machine communications. She is a Reviewer for several IEEE 882 and ACM conferences and journals.

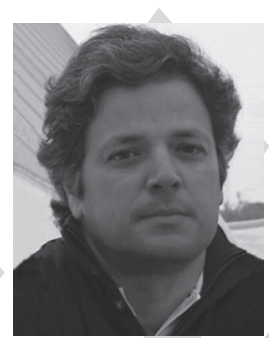

João P. Silva Cunha (S'86-M'90-SM'04) received 884 the Electronics and Telecommunications Engineer- 885 ing degree, the Ph.D. degree, and the "Agregação" 886 degree in electrical engineering from the University 887 of Aveiro, Portugal, in 1989, 1996, and 2009, respec- 888 tively. He is currently an Associate Professor of bio- 889 engineering and electrical and computer engineering 890 with the University of Porto, Portugal; a member 891 of the University of Porto Centre of Competence in 892 Future Cities; and a Senior Researcher at the INESC- 893 TEC Associate Laboratory (http://www.inesctec.pt), 894 where he created the Biomedical Research and Innovation (BRAIN) re- 895 search group and cofounded the Center for Biomedical Engineering Research 896 (C-BER) that aggregates $\sim 30$ researchers. He currently serves as a Codirector 897 of the Bioengineering M.Sc. Program at FEUP and as a Scientific Director 898 of the Carnegie-Mellon|Portugal program (http://www.cmuportugal.org) where 899 he has been a faculty member since 2007 . He cofounded in 2007 the spin- 900 off company Biodevices SA (http://www.biodevices.pt) to bring to the market 901 innovative biomedical technology developed for several years in his laboratory. 902 $\mathrm{He}$ is the author or coauthor of more than 250 scientific publications. He is 903 Senior Member of the IEEE, where he joined the Engineering in Medicine and 904 Biology Society (EMBS) in 1986 as a student member.

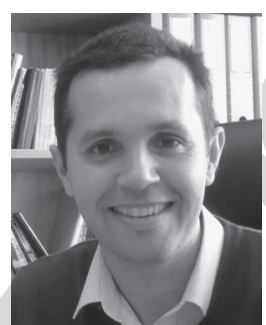

João Barros (S'98-M'04-SM'11) received his un- 906 dergraduate education in electrical and computer 907 engineering from the University of Porto, Porto, 908 Portugal, and Universitaet Karlsruhe, Karlsruhe, 909 Germany, and the Ph.D. degree in electrical engi- 910 neering and information technology from Technische 911 Universitaet Munich, Germany. He is currently an As 912 sociate Professor of electrical and computer engi- 913 neering with the University of Porto and the Found- 914 ing Director of the Institute for Telecommunications 915 (IT), Porto. He also teaches at the Porto Business 916 School and cofounded two recent startups, Streambolico and Veniam, commer- 917 cializing wireless video and vehicular communication technologies, respectively. 918 
AUTHOR QUERY

NO QUERY. 


\title{
A Mobile Sensing Approach to Stress Detection and Memory Activation for Public Bus Drivers
}

\author{
João G. P. Rodrigues, Student Member, IEEE, Mariana Kaiseler, Ana Aguiar, Member, IEEE, \\ João P. Silva Cunha, Senior Member, IEEE, and João Barros, Senior Member, IEEE
}

\begin{abstract}
5 Abstract-The experience of daily stress among bus drivers has 6 shown to affect physical and psychological health, and can im7 pact driving behavior and overall road safety. Although previous 8 research consistently supports these findings, little attention has 9 been dedicated to the design of a stress detection method able 10 to synchronize physiological and psychological stress responses of 11 public bus drivers in their day-to-day routine work. To overcome 12 this limitation, we propose a mobile sensing approach to detect 13 georeferenced stress responses and facilitate memory recall of 14 the stressful situations. Data were collected among public bus 15 drivers in the city of Porto, Portugal $(145 \mathrm{~h}, 36$ bus drivers, $16+2300 \mathbf{~ k m})$, and results supported the validation of our approach 17 among this population and allowed us to determine specific stres18 sor categories within certain areas of the city. Furthermore, data 19 collected throughout the city allowed us to produce a citywide 20 "stress map" that can be used for spotting areas in need of local 21 authority intervention. The enriching findings suggest that our 22 system can be a promising tool to support applied occupational 23 health interventions for public bus drivers and guide authorities' 24 interventions to improve these aspects in "future" cities.
\end{abstract}

25 Index Terms-Public transportation, driver, stress detection, 26 wearable technologies, georeferenced data analysis.

\section{INTRODUCTION}

29 RIVER behavior constitutes a major concern in road 30 safety research and policy. Since buses are one of the most 31 used modes of public transportation worldwide, the behavior

Manuscript received May 15, 2014; revised September 21, 2014 and February 19, 2015; accepted May 29, 2015. This work was supported in part by Instituto de Telecomunicações through the R\&D Unit UID/EEA/50008/2013; by Fundo Europeu de Desenvolvimento Regional (FEDER) through Programa Operacional do Norte (ON2); by the applicable financial framework FCT/MEC (PIDDAC) through national funds, within projects VOCE PTDC/EEAELC/121018/2010, FCOMP-01-0124-FEDER-037281, I-CITY Project-ICT for Future Mobility NORTE-07-0124-FEDER-000064, and PTDC/EEIELC/2760/2012 and grants SFRH/BD/62537/2009 and SFRH/BI/51845/2012; and by the European FP7 Project-Future Cities: FP7-REGPOT-2012-2013-1. The Associate Editor for this paper was A. Amditis.

J. G. P. Rodrigues, A. Aguiar, and J. Barros are with the Instituto de Telecomunicações, Departamento de Engenharia Eletrotécnica e de Computadores, Faculdade de Engenharia da Universidade do Porto, 4200-465 Porto, Portugal.

M. Kaiseler is with the Institute for Sport, Physical Activity and Leisure, Leeds Beckett University, Leeds LS1 3HE, U.K., and also with the Instituto de Telecomunicações, Departamento de Engenharia Eletrotécnica e de Computadores, Faculdade de Engenharia da Universidade do Porto, 4200-465 Porto, Portugal.

J. P. S. Cunha is with the Instituto de Engenharia de Sistemas e Computadores-Tecnologia e Ciencia (INESC TEC), Departamento de Engenharia Eletrotécnica e de Computadores, Faculdade de Engenharia da Universidade do Porto, 4200-465 Porto, Portugal.

Color versions of one or more of the figures in this paper are available online at http://ieeexplore.ieee.org.

Digital Object Identifier 10.1109/TITS.2015.2445314 of bus drivers and their occupational health becomes a critical 32 priority in overall road safety [1].

Epidemiological evidence from several studies conducted 34 mainly in North America and in Western Europe showed that 35 urban bus drivers have substantially higher mortality rates and 36 higher risk to develop physical and psychological diseases in 37 comparison to many other occupational groups [2]. In agree- 38 ment with this findings, a meta-analysis by Tse et al. [1] 39 reviewing fifty years of research in the area of bus driver 40 well-being concluded that this population is exposed to several 41 sources of stress over time. These can be distinguished in 42 three main categories: physical environment, job design and 43 organizational issues. Physical environment includes sources 44 of stress related with cabin ergonomics, exposure to noise, 45 weather conditions, threat of physical violence, and traffic con- 46 gestion aspects. Job design includes responsibility for security 47 and schedule obedience, working in shifts, long periods of 48 social isolation, ticket selling and control. Organizational issues 49 are related to bus drivers low autonomy and limited decision- 50 making authority. Finally, bus drivers profession is associated 51 with high sedentarism levels, which is known to be a major 52 cause for cardiovascular diseases [3].

The task of driving involves considerable strain for bus 54 drivers, ranging from the needed awareness to safeguard pas- 55 sengers, to traffic hazards [4]. The diversity of daily demands 56 faced by this population causes detrimental effects to their 57 physical and psychological health and well-being, as supported 58 by studies conducted in the occupational [5], ergonomic [6] and 59 biomedical areas [7]. Furthermore, it can also increase the risk 60 of accidents, decreasing overall road safety [1]. Also, stress 61 caused by emotional upsets has been associated with several 62 incidents among drivers [8]. This is probably explained by the 63 fact that emotional states of anger and frustration can increase 64 driver distraction and impair driving performance [9]. Addition- 65 ally, bus drivers role is often conceptualized as high in demands 66 (i.e., traffic congestion, rotating shift patterns, negative passen- 67 ger interaction, tight running times, workload demands, etc.) 68 and low in control with respect to limited decision latitude [6]. 69 This is a main cause for psychological problems [2] and cardio- 70 vascular diseases [10].

In agreement with this idea, an investigation by Baevskii et al. 72 [7] aiming to study the use of principles of prenosological 73 diagnosis for assessing the functional state of the body, has 74 found that bus drivers experienced chronic occupational stress 75 leading to exhaustion of regulatory mechanisms and to rapid 76 development of cardiovascular pathology. As explained by the 77 authors, long-term mental and psychoemotional tension in bus 78 
79 drivers was associated with occupational stress, and leads to 80 the worsening of psychophysiological and cardiorespiratory 81 function of the body. The degree of stress was assessed in this 82 study based on analysis of Heart Rate Variability (HRV).

83 While there is no definitive method of directly assessing 84 physiological stress levels, many techniques have been iden85 tified in the literature, such as heart rate and HRV metrics, 86 electrodermal activity, respiration rate, electromyography and 87 blood volume pressure [11]-[14]. Their results suggest that 88 stress events do indeed cause a reaction perceivable in physio89 logical signals, and that using multiple physiological inputs and 90 incorporating driving event information can greatly increase 91 drivers' stress detection accuracy [15], [16].

92 Although, one can question the ecological validity and re93 liability of driver stress measures collected in laboratory con94 ditions [17]. In opposition, stress assessment research among 95 drivers should take place in ecological settings including non96 intrusive physiologic stress monitoring. Recent advances in 97 noninvasive measurement techniques allowed the progression 98 of human developmental stress research [18], including ambu99 latory monitoring of cardiovascular function [19]-[21]. HRV 100 can be calculated from the Electrocardiogram (ECG), and is 101 reported to be an accurate measure of stress [13]. Recent studies 102 were able to correlate stress with some non-linear HRV features 103 [22], while time-domain and frequency-domain features ex104 tracted from HRV have been validated multiple times as stress 105 indicators in the last decades [13], [14], [23].

106 Nevertheless, stress assessment in ecological settings among 107 bus drivers is not always an easy task, mainly due to difficulties 108 faced when aiming to collect their physiologic and psychologi$109 \mathrm{cal}$ stress responses during operation of public vehicles in urban 110 centers [24]. Previous research in this area [25], [26] associ111 ated physiologic (e.g., blood pressure levels, pulse, and urine 112 samples) and psychologic (e.g., self-report and/or researchers 113 observation) measures of stress, and data was collected during 114 bus drivers rest periods. Although these studies provided a 115 crucial contribution to the understanding of daily stress among 116 bus drivers, they are plagued by limitations highlighted below. 117 Primarily, physiologic measures used do not include HRV, 118 considered to be one of the most viable physiologic assessments 119 of stress [14], [23]. Secondly, these research designs failed to 120 understand the physiologic and psychologic impact of a specific 121 source of stress on the driver [27]. Thirdly, the retrospective 122 self-report assessments of sources of stress at the end of a 123 working day may be plagued by attention and memory bias, 124 limiting the driver ability to recall acute stressful events [28]. 125 It is well known that the experience of stress affects quality 126 of memory recall [29]. Furthermore, bus drivers deal with 127 numerous tasks and challenges throughout a day at work (e.g., 128 driving, interaction with passengers and other drivers). Hence, 129 previous research has shown significant discrepancies between 130 real-time assessments and retrospective recall [30], questioning 131 how accurate and valid are results that rely merely on bus 132 drivers memory construction and retrieval.

133 Towards this goal, the current paper proposes an interdis134 ciplinary method that combines physiologic, psychologic and 135 georeferenced data to investigate sources of stress faced by bus 136 drivers while driving in an ecological setting on a daily work basis. Our contribution includes the design of stress assessment 137 software, adapted to the routine needs of bus drivers, and com- 138 bines non-intrusive, user friendly and reliable physiologic and 139 psychologic research methods, providing a continuous daily 140 monitoring of the driver during the course of a day at work. To 141 overcome previous retrospective self-report assessments among 142 bus drivers, our methodology provides a digital contextualiza- 143 tion of potential sources of stress, including environmental cues 144 to trigger memory retrieval [31]. Furthermore, this information 145 is synchronized with the physiologic response for each stressor 146 and the georeferenced location.

Hence, findings will benefit future evaluation of stress 148 sources among bus drivers and will foster the design of efficient 149 occupational health and local road safety interventions.

\section{Methodology}

In this section we describe the technology and methodology 152 that was iteratively improved by real-world experiments with 153 professional bus drivers in the city of Porto, Portugal.

\section{A. Sensing Platform}

Our project targeted a large population, and thus our plat- 156 form was designed to be very easy to use and have very low 157 intrusiveness. These were critical for the wide acceptance and 158 participation we achieved, with 36 volunteers out of 37 drivers 159 introduced to the project.

1) Physiologic Sensors: One kit of equipment was pro- 161 vided to each bus driver, including a VitalJacket, ${ }^{1}$ disposable 162 electrodes, a Global Positioning System (GPS) receiver and a 163 netbook PC. The Vital Jacket (VJ) is a wearable bio-monitoring 164 platform in the form of a $\mathrm{t}$-shirt that provides real time 165 electrocardiogram (ECG) with $500 \mathrm{~Hz}$ sampling rate, 3 axis 166 accelerometer and an event push-button [21], [32]. This data 167 is transmitted to the netbook via Bluetooth from a small box 168 embedded in an easily accessible pocket on the t-shirt.

2) Self-Report Measures: Health and demographic question- 170 naires were completed by participants. This data was used 171 to analyze the impact that demographic metrics have on the 172 drivers' physiologic response (Section IV-C).

Furthermore, bus drivers provided a description of each 174 potential stressor, followed by a stress intensity rating, based 175 on their appraisal of the particular situation. Potential stressful 176 situations were either detected by the system or tagged by the 177 drivers using the push-button incorporated in the VJ. Stress 178 intensity was assessed using a "stress thermometer" where the 179 participant dissected a $10 \mathrm{~cm}$ bipolar line anchored by two 180 statements ("not at all stressful" vs. "extremely stressful"). 181 The "stress thermometer" has demonstrated normal distribution 182 properties and adequate variability in previous stress assess- 183 ment research [33], [34].

3) System Architecture: The GPS receiver used was placed 185 near a bus window and transmits information to the netbook 186 via Bluetooth. A small and lightweight netbook, chosen for its 187

\footnotetext{
${ }^{1}$ BioDevices S.A., www.vitaljacket.com.
} 


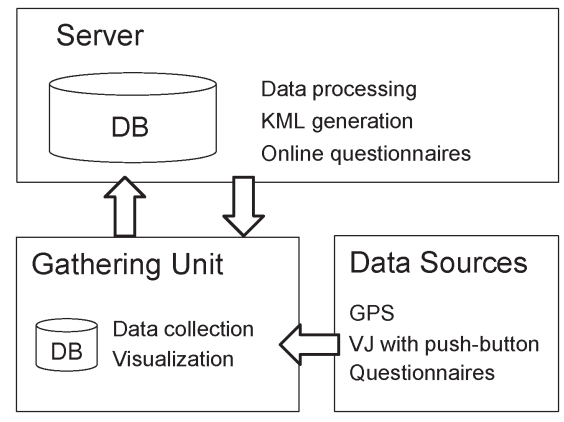

Fig. 1. Hardware architecture.

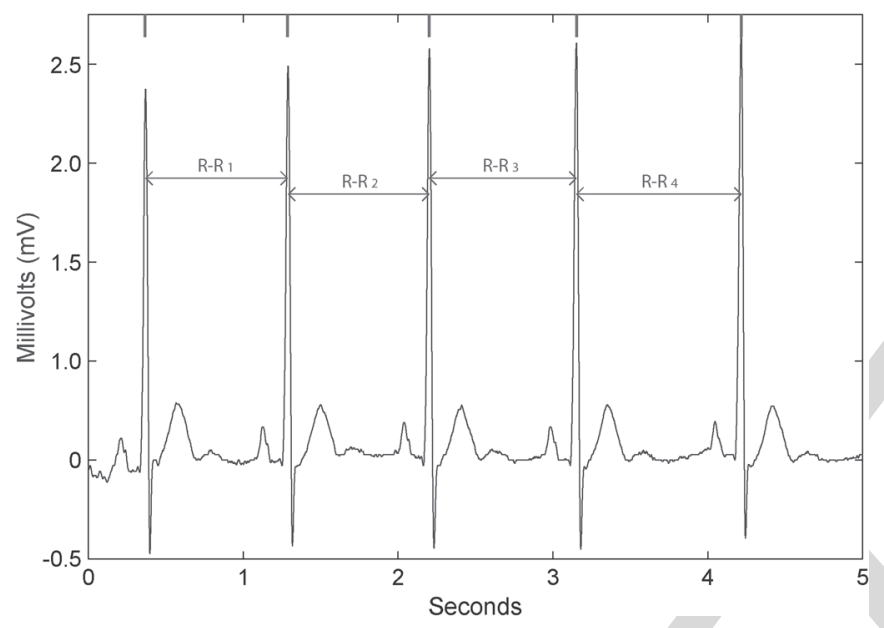

Fig. 2. Sample ECG signal collected from a bus driver and R-R measures.

188 portability, served as the gathering unit. Data processing was 189 performed on a cloud server to increase processing speed. The 190 netbook was used further for visualization in the recall phase 191 (see Section II-B), and the required Internet connectivity was 192 provided by a $3 \mathrm{G}$ network adapter.

193 The architecture of the system designed and implemented 194 to integrate the previous materials is shown in Fig. 1. This 195 architecture and gathering capabilities, such as sensor-data syn196 chronization, reliability and communications have been tested 197 and validated in previous work [35].

198 4) Signal Processing Software: The processing of the ECG 199 signal was performed using the open-source library Phys200 ioToolkit from Physionet [36], which follows the recommen201 dations proposed by the Task Force of The European Society 202 of Cardiology and The North American Society of Pacing and 203 Electrophysiology [13].

204 We used the GQRS tool from the library to extract heartbeat 205 information from the ECG. Fig. 2 shows a 5 second ECG seg206 ment with the $\mathrm{R}$ peaks marked at the top. This tool determines 207 the moment of the peaks for each heartbeat and outputs the 208 inter-beat intervals (R-R) in a format compatible with other 209 Physionet tools.

210 Extra processing and filtering of the cardiac signal was 211 required, as explained in Section III-C, due to the presence of 212 very noisy signals, which can occur in real world research.

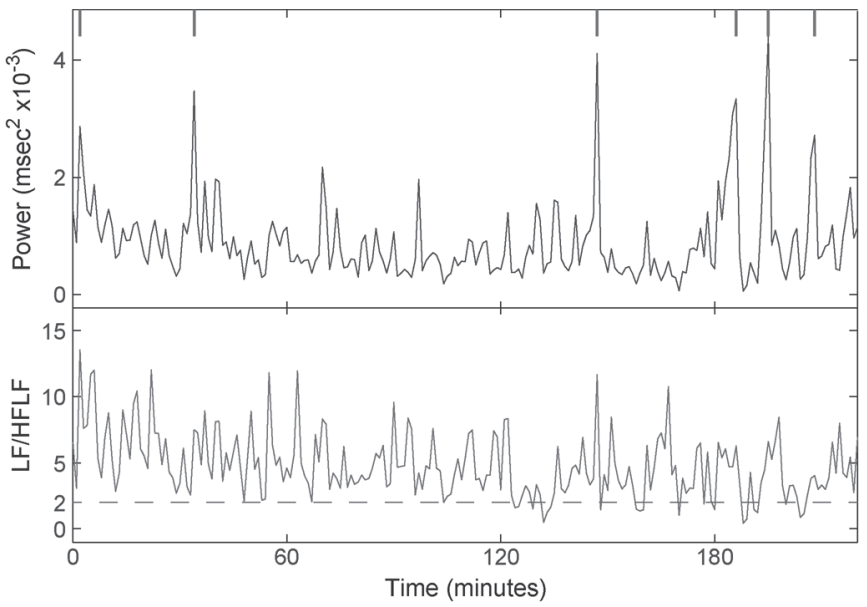

Fig. 3. Low Frequency Power and the ratio between Low Frequency and High Frequency power, for a 3 hour long trip. We use the standardized LF Power to detect stressful events, marked in the top horizontal axis.

We used the HRV Toolkit from Physionet to perform time- 213 domain and frequency-domain analysis of the heart rate in- 214 formation, as suggested by the Task Force of The European 215 Society of Cardiology and The North American Society of 216 Pacing and Electrophysiology [13]. We performed the analysis 217 using a window size of $100 \mathrm{~s}$ with a shift of $60 \mathrm{~s}$ between 218 consecutive windows, and the results were stored for further 219 statistical analysis (which we denominate HRV blocks). We 220 decided to use overlapping windows to improve the time ac- 221 curacy of the results, but we downsample the results when 222 independence between samples is required (see Section III-C). 223 The window size of $100 \mathrm{~s}$ was chosen in order to have a $0.02 \mathrm{~Hz} 224$ of frequency resolution in the frequency-domain results without 225 upsampling. Among others, the metrics include the average 226 normal-to-normal (NN) intervals, the standard deviation of 227 these NN intervals, their low frequency spectral power (LF) 228 between $0.04 \mathrm{~Hz}$ and $0.15 \mathrm{~Hz}$, the high frequency power (HF) 229 between $0.15 \mathrm{~Hz}$ and $0.4 \mathrm{~Hz}$, and the ratio LF/HF.

The spectral power of different frequency bands is specially 231 important to our study, because the power in the HF band is 232 mainly mediated by the parasympathetic system and encom- 233 passes respiratory sinus arrhythmia, but the LF band is medi- 234 ated by both the parasympathetic and sympathetic components, 235 and so they might provide a robust way to assess individual 236 stress [37]. Fig. 3 shows an example of the evolution of the 237 LF power and the LF/HF ratio, which are the two metrics most 238 correlated to stress according to [12] and [23]. The figure shows 239 that spikes are more distinct in the LF than the LF/HF case. A 240 statistical analysis (Section III) confirmed this, leading us to use 241 the LF power as a stress indicator.

5) Detecting Stressful Events: Potentially stressful events 243 were selected from all the moments the driver pushed the button 244 on the $\mathrm{VJ}$, combined with additional 10 blocks with the driver's 245 highest physiologic stress (LF component) but separated at least 246 5 minutes between each other.

6) Enquiry and Visualization Tools: The processed ECG 248 data, together with the GPS information, was used to generate 249 a map at the end of each driver's shift. 


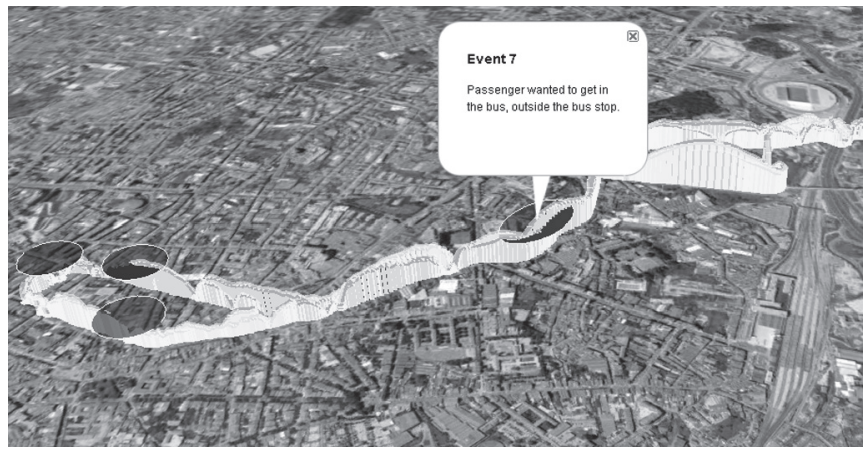

Fig. 4. Visualization of a trip and stress events in Google Earth. The height of the traces represents bus speed, ellipses denotes events.

251 The map was visualized using Google Earth (Fig. 4), pro252 viding a straightforward approach to overlay spatial data and 253 correlate different types of information. Free camera move254 ments and a time toolbar, used to select a time interval window 255 to be displayed, allowed to easily analyze the detected events 256 and their context. To facilitate memory recall, we overlaid 257 information about location and time of the events, as well as the 258 speed of the bus in the whole trip, plotted using a line segment 259 over the map with the height of the line representing speed. 260 By displaying the speed profile for every second of the trip, the 261 driver and researcher could easily identify bus stops and driving 262 events information, such as aggressive braking, accelerations 263 (as in Rigas et al. [16]) and others, aiding them recall and 264 characterize the events. In the map, the detected potentially 265 stressful events were displayed as ellipses spanning over the 266 area traveled during the corresponding 100 s HRV block.

267 The Internet connection from the 3G network adapter was 268 used to access Google Earth and refresh the maps and to 269 synchronize the driver's self-report data to the server. Moreover, 270 the netbook also leveraged this Internet connection to speed up 271 the processing of the ECG signal, sending the raw data to a 272 server that performed all the needed computation and gener273 ated the maps. This upload and cloud processing took around 2744 minutes for a 6 hour work shift. If the computation had been 275 done locally, it would have taken around 15 minutes for the 276 same workload.

\section{B. Procedure}

278 On the day prior to data collection, participants completed 279 a demographic and health questionnaire, and received a kit 280 containing the required equipment. At this time they were given 281 a detailed explanation of the procedures by a researcher. On 282 the data collection day, the bus driver followed the workflow 283 depicted in Fig. 5, wearing the VitalJacket and turning on the 284 netbook and GPS receiver at the beginning of the work shift. 285 Following this procedure, the bus driver was ready to start 286 his work shift, carrying the kit for a full day. The participant 287 was instructed to press the button on the VitalJacket in case of 288 appraising a potentially stressful event during the day, affecting 289 his or the passengers well-being. At the end of the shift, a 290 researcher met the participant at the station, and ran the cloud 291 processing algorithms over the gathered data. A map was then produced displaying the information for the full workday of that 292 participant, as described in Section II-A6.

For each of the displayed ellipses, the driver visualized 294 the exact location and extra information using Google Earth 295 (Fig. 6). For the cases when the participant could remember 296 the event, he was asked to recall that particular situation, and 297 to provide a brief description followed by the stress intensity 298 evaluation for that particular event. The description of the 299 events and stress intensity evaluation were completed in the 300 netbook, but stored and synchronized with the physiologic data 301 on the cloud server.

302

The protocol was designed to obtain the following indepen- 303 dent data sets to help in the detection and categorization of the 304 events:

- Tagged events, providing annotations of on-site self- 307 reported stressors including a description of the situation 308 experienced and stress intensity evaluation; $\quad 309$

- Physiologic responses measured with biomedical 310 sensors-HRV blocks;

311

- Location and velocity information assessed from GPS 312 data, used to detect driving events and facilitate memory 313 retrieval.

314

- Short annotations for every stressful event detected by the 315 system and confirmed by the driver as stressful, includ- 316 ing a description of the situation experienced and stress 317 intensity evaluation.

This method provided an accurate connection between the 319 georeferenced data, description of the stressor experienced and 320 stress appraisal evaluation for a particular stressor, synchro- 321 nized with physiologic and driving response data. The ellipses 322 provided a general vicinity to the memory retrieval of the event, 323 contextualizing time and location information. Additionally, 324 the method allowed the driver to isolate certain events during 325 the working day by pushing the button. These were saved in the 326 system and available for description and stress intensity evalu- 327 ation later at the end of the work shift.

\section{DATA ANALYSIS}

Thirty-six male professional bus drivers, aged between 29331 and 55 years old $($ Mean $=41$; Standard Deviation $=6.5)$ with 332 experience in bus driving between 3 and 25 years $(M=13 ; 333$ $\mathrm{SD}=6.0$ ), participated in this study. All participants worked 334 for the major transportation company in the city of Porto, 335 Portugal. The exclusion criteria for the study were participants 336 having a history of cardiovascular disease and/or taking pre- 337 scription drugs known to affect cardiovascular function. Partic- 338 ipants volunteering to participate in the study were instructed 339 to perform no changes in their daily routine, such as sport 340 activities and caffeine, nicotine and food consumption.

341

Following approval of the study by the bus company ad- 342 ministration, bus drivers were invited to participate. For this 343 purpose a presentation session was organized by researchers, 344 explaining the aim and protocol of the study. Participants 345 provided informed consent forms prior to participation. 


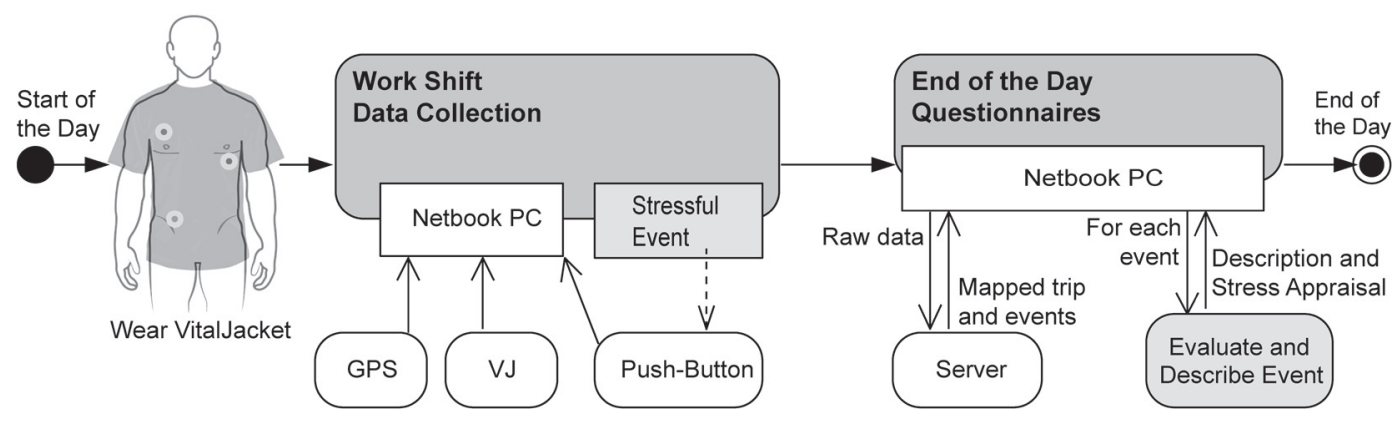

Fig. 5. Workflow on daily data collection.

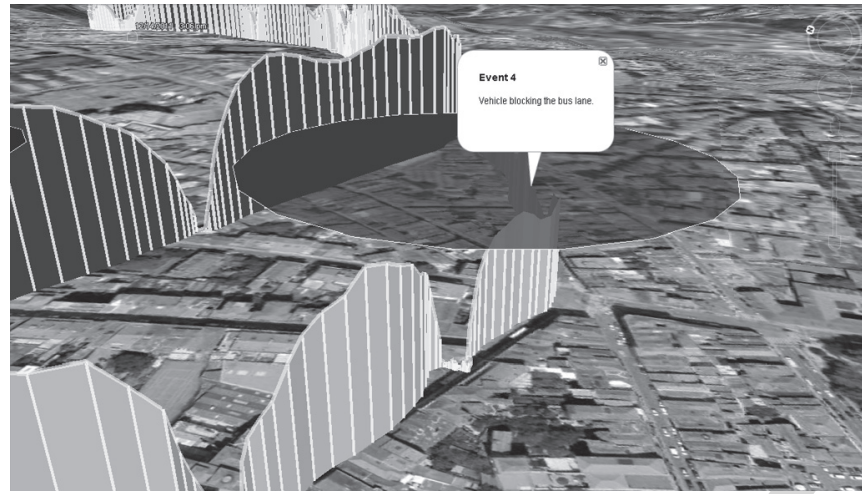

Fig. 6. Close-up of a stress event in Google Earth. The height of the traces represents bus speed.

347 Data was collected for each bus driver over a full working 348 day, corresponding to approximately 5 hours of driving, divided 349 in one or two daytime shifts occurring between 8 AM and 8 PM. 350 In total, this study gathered 151 hours of data, including $500 \mathrm{~Hz}$ $351 \mathrm{ECG}$ and location information stored every second that spanned 352 more than $2.500 \mathrm{kms}$.

\section{B. Stressor Categories}

354 Each situation of stress described by the drivers in the 86 355 events was subjected to a content analysis to identify stressors 356 categories. The identified categories are similar to a great extent 357 to the job hassles reported by previous research [27], with a few 358 exceptions discussed in Section V.

359 The first two authors then independently assigned each event 360 into 5 major stressor categories or event types.

361

362 1) Social interactions (e.g., with passengers or friends);

363 2) Unexpected situations (e.g., mechanical failures, driving 364 mistakes, unexpected changes);

365 3) Other drivers or pedestrians behaviors (e.g., other drivers

366 risky behaviors and lack of politeness);

367 4) Events that impact time schedule (e.g., traffic congestion);

368 5) Difficult driving due to urban planning (e.g., narrow roads 369 and tight corners).

370 A reliability check showed a level of agreement of $98.8 \%$ be371 tween both researchers after the first categorization. Following 372 some discussion, this agreement increased to $100 \%$.
C. Filtering and Processing the Physiologic Data

1) Synchronizing the VJ and GPS Clock: The Physionet 374 library can process the cardiac signal and outputs the metrics 375 we need. However, some extra steps were required in order to 376 synchronize the Physionet output with our GPS data. 377

We used the GQRS tool from Physionet to detect heart beats, 378 which takes the ECG signal as input with a specified starting 379 time and sample frequency, and outputs the timestamps of 380 every detected beat. Even though the VitalJacket, our ECG 381 sensor, has a fixed $500 \mathrm{~Hz}$ sampling rate, small errors in the 382 VJ clock precision and in the Bluetooth communication can 383 cause discrepancies between the timestamps and duration of 384 the ECG and the GPS data. This clock drift is negligible at 385 the beginning of a trip, since a starting timestamp is given 386 to the application, but naturally increases as the time passes, 387 and sometimes resulted in errors of more than 15 minutes at 388 the end of the $6 \mathrm{~h}$ trips in our pilot experiments. A small 389 desynchronization between the VJ and GPS clocks can cause 390 a huge misplacement of a stressful event, since buses can travel 391 at up to $50 \mathrm{~km} / \mathrm{h}(14 \mathrm{~m} / \mathrm{s})$

392

To correct this synchronization issue our processing algo- 393 rithm keeps track of the GPS clock and also of a virtual one 394 that follows the beat-detector fixed $1 / 500 \mathrm{~s}$ per data sample. The 395 differences between both clocks is constantly analyzed, and the 396 ECG stream is split and given a new corrected timestamp every 397 time a shift of more than $10 \mathrm{~s}$ is detected.

398

2) Detecting Noisy ECG Data: Another problem we de- 399 tected in our pilot experiments when processing the data was 400 ECG noise. The heartbeat detectors perform poorly in the 401 presence of very noisy signals that can occur in real world 402 scenarios like ours, leading to the detection of false-positive 403 stressful events. There are many sources of noise in a real world 404 environment, such as from other muscular activity or electrode 405 misplacement, which can significantly reduce the accuracy of 406 the heartbeat detection algorithms.

407

We implemented a Standard Deviation (SD) filter to detect 408 extremely noisy blocks of data and improve the reliability of 409 the ECG data. This filter calculates the SD of the raw ECG 410 every second (500 samples), discarding an HRV block from 411 the analysis if it contains any second with an SD higher than 412 a threshold. The filter successfully detected the trips belonging 413 to 2 drivers who misplaced the electrode patches, and also other 414 3 trips that presented problems with the electrodes' connection 415 after some point in the middle of the trip. After analyzing these 416 
417 trips, the threshold was set as the 90th percentile of all of our 418 data, eliminating the $10 \%$ noisiest ECG data gathered in our 419 real world scenario. The SD filter was applied to $151 \mathrm{~h}$ of 420 gathered data, resulting in 1470 discarded HRV blocks. From 421 these, 1349 (92\%) belonged to 5 trip segments with problems 422 in the electrode patches.

423 3) Push-Button Time Correction: Another filtering step was 424 the correction of tagged events' timestamps. This consisted in 425 correlating the push-button events with the correct HRV block 426 of physiologic sensor data by analyzing the driver description of 427 the event and surrounding trip data, such as location and speed. 428 Most of the events were associated with the block that imme429 diately preceded it, meaning that the drivers pressed the button 430 right after they experienced a stressful situation. However, in 431 some cases they were associated with the following block, 432 because some drivers pressed the button when approaching a 433 known dangerous place.

434 4) HRV Metrics Standardization: Different drivers have dif435 ferent cardiac characteristics and baselines, preventing us from 436 comparing HRV metrics between multiple drivers. Since we 437 could not collect a baseline for each driver in a relaxed and 438 controlled environment, we decided to standardized the cardiac 439 metrics per driver. To this end, the HRV metrics of each driver's 440 entire collection day were transformed to have zero mean and 441 unit variance.

442 5) Downsampling to Independence: The final step in our 443 processing algorithm was the downsampling of the HRV blocks 444 for each driver in order to increase independence between 445 samples. The recalled events were already selected with at least $4465 \mathrm{~min}$ of data between them. However, the rest of the ECG 447 was analyzed every minute but with a window size of $100 \mathrm{~s}$, 448 resulting in $40 \mathrm{~s}$ overlap between HRV blocks, and producing 449 a dependent dataset of HRV metrics. To make the HRV blocks 450 independent, the processed and filtered blocks were downsam451 pled for each driver, removing the minimum number of blocks 452 that guarantees the same 5 min distance between HRV blocks 453 or any recalled or tagged events.

\section{RESUlts}

455 We gathered a total of 9081 HRV Blocks, from which 1470 456 were filtered as noise and 6050 were removed in the downsam457 pling process. From the 36 drivers, 2 had misplaced electrodes 458 providing no useful ECG data and other 2 forgot to turn on 459 the GPS device. 29 events were tagged on-site as stressful by 46011 drivers. Some drivers forgot they were being monitored and 461 thus forgot to press the button in stressful situations, others were 462 distracted dealing with the situations.

463 To facilitate the events recall, 320 distinct blocks were iden464 tified by the system and shown to the 32 drivers in the map 465 at the end of the day. From these, 57 blocks were recalled as 466 stressful events and evaluated by 27 bus drivers, 2 drivers did 467 not recall any additional events besides the ones they tagged, 468 and 3 stated they did not experience any stressful situations 469 during their work shift.

470 Our final dataset to be analyzed contains stress information 471 from 29 drivers, with 29 on-site tagged events, 57 events

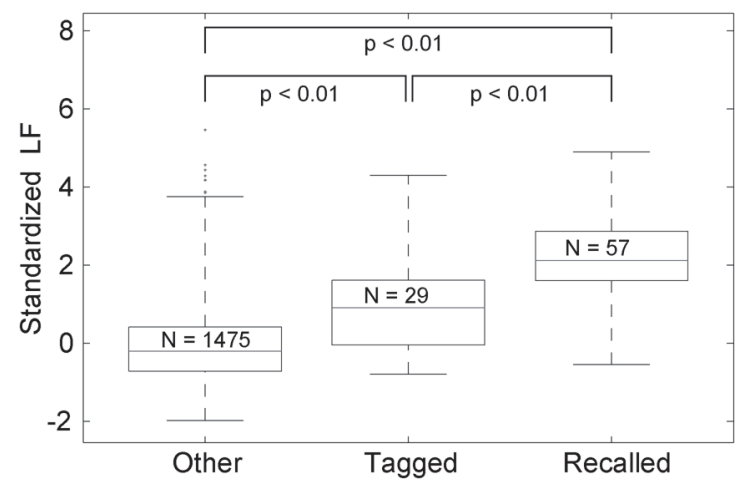

Fig. 7. Distribution of calculated stress between other blocks, tagged events, and events recalled at the end of the day.

recalled at the end of the day, and other 1475 HRV blocks not 472 identified as stressful. Thus, a total of 1561 independent rows 473 of data standardized per driver.

Due to non-normalized distributions of the data, we used 475 non-parametric tests. The Mann-Whitney U-Test [38] was 476 chosen to compare the distributions of two populations, the 477 Kruskal-Wallis Test [39] to verify if more than two popula- 478 tions have the same distributions, and the Kendall's Tau [40] 479 to check for statistical dependence between variables in the 480 same population. To this end, multiple pairwise MannWhitney 481 U-Tests were conducted to analyze differences in the main 482 HRV metrics between the samples classified as tagged events, 483 recalled events and others. Kruskal-Wallis Test was conducted 484 to test for differences in the LF spectral power across stressor 485 categories in both self-reported and cardiac stress responses. 486 Kendall's Tau rank correlation test was used to search for 487 statistical association between demographic and physiologic 488 variables.

\section{A. Physiologic vs Recalled Stress Assessment}

Our system used the LF component of the interbeat intervals 491 as a stress indicator, as proposed by [12] and [23]. To validate 492 this proposition, we compared the LF frequency component of 493 all blocks, the tagged events and the stress events recalled at the 494 end of the day (Fig. 7).

The MannWhitney U-Test showed significant difference be- 496 tween the distributions of LF power for other and tagged events 497 $\left(\mathrm{z}=-4.91, \mathrm{p}=9.16^{-7}\right)$, indicating that there is a significant 498 increase of the LF power during events appraised as stressful 499 by the driver. The recalled events also presented a statistically 500 higher LF component than the tagged events $(\mathrm{z}=-4.85, \mathrm{p}=501$ $1.23^{-6}$ ), even when analyzing only the 11 drivers who tagged 502 events.

The same statistical analysis between tagged and other events 504 was performed for every HRV metric, and some are presented in 505 Table I. The metric that showed the most statistically significant 506 difference was the LF power, followed by the time-domain 507 metrics that detect variability, such as standard deviation of 508 heart beat intervals. 
TABLE I

Distribution Tests' Results Between Other and TAgged EVENTS OF DIFFERENT HRV METRICS FROM THE HRV TOOLKIT

\begin{tabular}{l|c|c|c|c|c|c}
\hline MannWhitney & AVNN & SDNN & pNN50 & LF & HF & LF/HF \\
$Z$ value & -0.68 & -4.19 & -2.75 & -4.91 & -2.39 & -1.42 \\
P value & 0.50 & $<\mathbf{0 . 0 1}$ & $<\mathbf{0 . 0 1}$ & $<\mathbf{0 . 0 1}$ & $\mathbf{0 . 0 2}$ & 0.16 \\
\hline
\end{tabular}

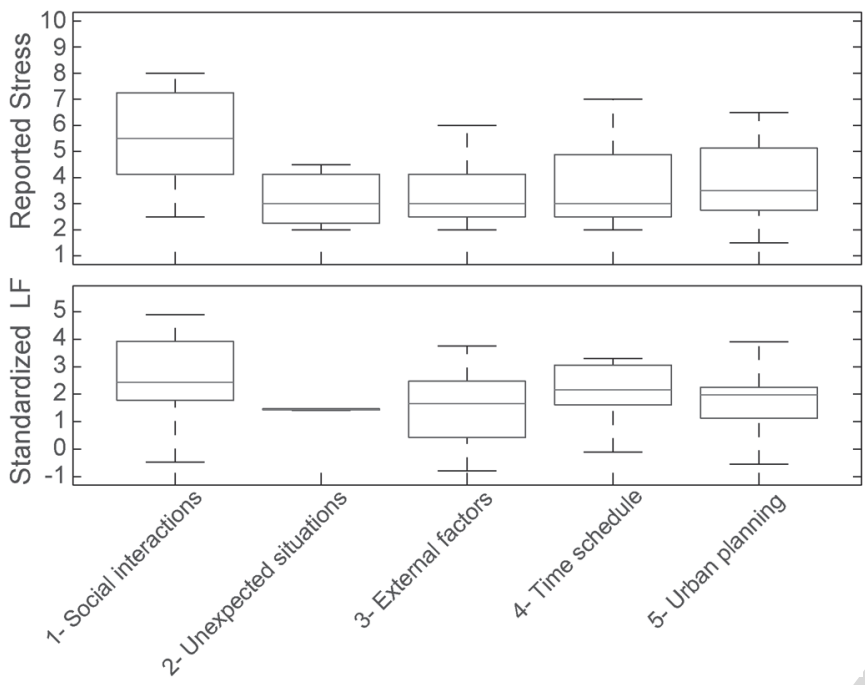

Fig. 8. Distribution of the stress level throughout the different stress categories, for both reported stress evaluated by the stress thermometer, and calculated from the ECG signal.

TABLE II

FREQUENCY ANALYSIS FOR REPORTED STRESSOR CATEGORIES: NUMBER OF REPORTS, FREQUENCY RELATIVE TO THE TOTAL Number of EVENTS, NuMber of Distinct Drivers THAT REPORTED THAT CATEGORY, AND CORRESPONDING RELATIVE FREQUENCY TO THE NUMBER OF DRIVERS

\begin{tabular}{l|c|c|c|c|c|c}
\hline Stressor Category & 1 & 2 & 3 & 4 & 5 & Total \\
\hline Total Count & 14 & 7 & 30 & 16 & 19 & 86 \\
Relative Frequency & $16 \%$ & $8 \%$ & $35 \%$ & $19 \%$ & $22 \%$ & \\
Drivers & 11 & 6 & 18 & 12 & 12 & 29 \\
Drivers Frequency & $38 \%$ & $21 \%$ & $62 \%$ & $41 \%$ & $41 \%$ & \\
\hline
\end{tabular}

\section{B. Analysis of Stressor Categories}

511 Fig. 8 shows an overview of the distributions for physiologic 512 and self-reported stress intensity evaluation for each stressor cat513 egory, introduced in Section III-B. An event was only considered 514 to be stressful when appraised by the bus driver as higher than 0 515 in the stress thermometer scale (51 of the 86 identified events). 516 The Kruskal-Wallis Test showed that no significant differ517 ences across stressor categories exist either for self-reported $518 X^{2}(4, N=51)=7.62 ; p=0.11$; or for cardiac stress re519 sponses $X^{2}(4, N=51)=4.82 ; p=0.31$.

520 Table II shows a frequency analysis of stress categories 521 combining all tagged and recalled events appraised as stressful 522 by bus drivers. Other drivers or pedestrians behaviors were the 523 most commonly reported source of stress, reported for $35 \%$ of 524 the recalled or tagged events and mentioned at least once by $52562 \%$ of the 29 bus drivers. Difficulty driving due to urban plan526 ning was the second most reported source of stress, reported for $52722 \%$ of the events recalled or tagged, and mentioned by $41 \%$ of 528 the drivers (12/29). Also, events that impact time schedule was 529 a frequently reported source of stress, accounting for $19 \%$ of 530 the events and mentioned by $41 \%$ of the drivers.
TABLE III

Kendall's TAu Test Results For DEMOgRaPhic AND Full-Day CARDiaC METRICS. P VAlues LOWER THAN 0.05 ARE MARKED AS BOOLEAN

\begin{tabular}{|l|cc|cc|cc|}
\hline & \multicolumn{2}{|c|}{ Age } & \multicolumn{2}{c|}{ Weight } & \multicolumn{2}{c|}{ Experience } \\
& Tau & P & Tau & P & Tau & P \\
\hline AvgAVNN & 0.0 & 0.84 & 0.3 & 0.06 & -0.3 & $\mathbf{0 . 0 2}$ \\
AvgSDNN & 0.0 & 0.87 & 0.1 & 0.72 & -0.3 & $\mathbf{0 . 0 1}$ \\
AvgLF & -0.1 & 0.32 & 0.1 & 0.63 & -0.3 & $\mathbf{0 . 0 4}$ \\
AvgHF & -0.2 & 0.09 & 0.1 & 0.45 & -0.3 & $\mathbf{0 . 0 2}$ \\
AvgLF/HF & 0.1 & 0.37 & -0.1 & 0.72 & 0.0 & 0.93 \\
\hline
\end{tabular}

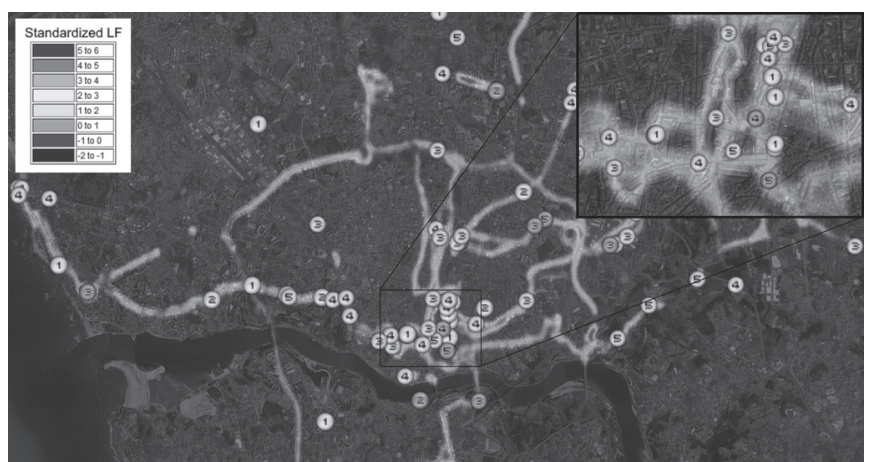

Fig. 9. Stress map of Porto with placemarks on detected stressful events. The numbers represent the event category, the darker marks are tagged events and lighter are events recalled at the end of the day.

\section{Questionnaires and per Driver Analysis}

In this project we also analyzed the questionnaires data 532 and their correlations with the cardiac metrics. We combined 533 the questionnaires answers with the HRV analysis over each 534 driver's full dataset, resulting in metrics such as a driver's 535 age, height, weight, years of experience as a bus driver, usual 536 exercise routine, and also the full day's average heart rate, 537 average spectral power for different frequencies, and others. $\quad 538$

To analyze the data we performed cross-correlation analysis 539 between all variables using Kendall's Tau $(\tau)$ rank correlation 540 test [40]. The main results are presented in Table III, with cor- 541 related variables resulting in a p-value lower than 0.05 marked 542 in bold.

The results show a strong correlation between the cardiac 544 metrics and the years of experience of the drivers, and not with 545 any other demographic metric.

\section{Geo-Referenced Stress Analysis}

Furthermore, the analysis of the tagged and recalled stress 548 events showed that more than $75 \%(65 / 86)$ of the stressors are 549 location-dependent, such as tight roads, low-visibility cross- 550 walks and drivers not respecting signalization on some cross- 551 roads. This data suggests that the geographic reference of 552 detected events provided by our method was efficient in facili- 553 tating bus drivers' memory retrieval, and also that it is possible 554 to provide valuable stress-maps to decision makers. With both 555 physiologic and psychologic stress assessment performed with 556 our methodology, we are able to map their intensity and detect 557 systematically stressful locations.

Fig. 9 shows a stress map of the city of Porto, where lighter 559 areas represents less stressful and darker areas represents highly 560 
561 stressful places. Also, darker symbols mark the spots where 562 stressful events were tagged, lighter ones were recalled at 563 the end of the day, and the numbers correspond to the event 564 category as stated in Section III-B. The map was generated by 565 clustering and averaging the Standardized LF information of 566 the HRV blocks. Additionally, in order to eliminate biases in the 567 cardiac data associated with physical activity, we discarded data 568 gathered while the bus was almost stopped (less than $5 \mathrm{~km} / \mathrm{h}$ ) 569 and only map clusters with data from at least 3 distinct drivers. 570 Based on Fig. 9 it is clear that the city downtown, near 571 the center of the map, is a stressful region with many highly572 stressful roads being detected in that dense urban zone. How573 ever we can also find other less obvious highly-stressful zones, 574 such as in the left-middle edge of the map, where a roundabout 575 caused a cardiac response in all of the 4 drivers that passed by 576 and even a tagged event from one of the drivers.

\section{Discussion}

578 The aim of the current paper was to investigate daily sources 579 of stress faced by bus drivers while driving in an ecologi580 cal setting during their daily work. Results suggest that the 581 proposed method is accurate in detecting psychological and 582 physiological stress responses. Despite the divergence in the 583 concept definition and assessment of stress, our findings are 584 consistent with previous research recommendations [41].

585 Particularly, results showed a significant increase of the LF 586 component of HRV during events appraised as stressful by the 587 driver, suggesting that the stress concept assessment can com588 bine both psychologic and physiologic dimensions of stress, 589 while also contemplating an integrative approach in the real 590 world. Contrary to the results presented by McCraty et al. [12] 591 and Healey and Picard [23], the LF/HF does not show a statisti592 cally different distribution between tagged stressful events and 593 other HRV blocks, which may be due to the higher HF noise 594 present in real word scenarios like the one in this study. This 595 indicates that the LF power is the best stress metric for our 596 scenario.

597 Regarding demographic factors and their impact on the 598 drivers' physiologic response, results indicate that years of 599 experience of the driver is an important factor to consider. 600 Surprisingly, even the age, which is correlated with the years 601 of experience, is not significantly correlated with the physio602 logic metrics. This suggests that, although cardiac response is 603 known to decrease with age [42], more experienced drivers (not 604 necessarily older ones) have less cardiac response to stressful 605 events and a smoother physiologic response throughout the 606 entire working day. Further research is required controlling for 607 bus drivers routes in order to confirm whether this finding is 608 due to effective coping strategies developed by this population 609 or the experience of different environmental demands.

610 In what concerns to sources of stress found in our study 611 (Section III-B), these are similar to a great extent to the job 612 hassles reported by Johansson et al. [27] among bus drivers 613 working in the city of Stockholm (e.g., traffic congestion, illegal 614 parking of vehicles, risky or impolite behaviors of other divers 615 or pedestrians, mechanical difficulties, timetable restrictions). 616 However, in the current study, social interactions with passen- gers or friends and bus driving mistakes were also reported 617 as stressors in $16 \%$ of the reported events and by $38 \%$ of the 618 drivers $(11 / 29)$. We believed that this fact may be mainly related 619 to the methods used in this study that facilitated the drivers 620 memory retrieval of events. On the other hand, previous re- 621 search methods used across studies relied on retrospective self- 622 reports following long periods of time what may had affected 623 the type of stressors reported. Additionally, other previous 624 studies were based on the researcher observations, whereas 625 our study relied on a more ecological setup and based on the 626 inputs of the drivers themselves, i.e. their own perceptions 627 and experiences of stress. As a result, stress categories such 628 as the experiences of interpersonal stressors are unlikely to 629 be reported by others, who merely described what they can 630 observe. Also, the constant presence of an observer may pro- 631 duce biased results, making the driver less likely to do driving 632 mistakes and avoid communicating with friends entering the 633 bus. Hence, we believe that the type of stress categories found 634 in this study complements the literature in the area and reinforce 635 the strengths of the methodology used to capture drivers acute 636 stressors experienced on a daily basis.

637

It is important to highlight that the current ecological method 638 culminates a previous limitation in the area of stress reactivity 639 assessment [43], and provides a crucial contribution to the study 640 of cardiovascular reactivity to stress in real world scenarios. 641 This is a fundamental relationship when investigating sources 642 of stress, critical to the etiology of cardiovascular disease [27]. 643 Furthermore, as suggested by Myin-Germeys et al. [44] stress 644 responses assessed in real life situations are more likely to be 645 closer to reality than those collected under laboratory settings. 646

Additionally, the inclusion of georeferenced information and 647 its visualization by bus drivers was a key aspect in this method- 648 ology, facilitating memory retrieval of the experienced situa- 649 tions, thus providing a detailed description and specificity of 650 stressors. To support this argument the proposed methodology 651 allowed the collection of 57 additional stressors in the city of 652 Porto, compared with only 29 voluntarily tagged by bus drivers. 653

In sum, the proposed methodology provides detailed infor- 654 mation of different stressors experienced by bus drivers, and 655 their specific location in a city. It is believed that this informa- 656 tion can induce evidence based decisions across a variety of 657 areas (e.g., ergonomics, security, management, technological, 658 public policy, psychologic and urban planning). Additionally, 659 the system is able to map exactly where in the city these events 660 have occurred and the average stress intensity for the sensed 661 areas, what is likely to result in more efficient decision making. 662 Furthermore, the mapped placemarks are clickable on Google 663 Earth, allowing decision makers to see detailed information of 664 each stress event, such as intensity and description.

\section{CONCLUSION}

666

We proposed an interdisciplinary methodology for assess- 667 ing sources of stress in professional bus drivers based on 668 the population's real world needs. The system was designed 669 by an interdisciplinary team, in cooperation with bus drivers 670 working in the city of Porto. The method validation was tested 671 among a sample of bus drivers in their day-to-day routine. 672 
673 Results showed that the methodology is successful in detecting 674 stressful events based on bus drivers' physiologic responses. 675 Furthermore, the system provides real world visual cues and 676 information, which seems to facilitate driver memory retrieval, 677 enriching description of stressful events, and findings provide 678 contextualized sources of stress within a city. Applied impli679 cations of this method will foster evidence based solutions at 680 enterprise, policy-makers and government levels, providing an 681 open approach to improvement and change towards developing 682 bus drivers' occupational health, improving driver performance, 683 and enhancing overall road safety. Theoretical implications of 684 this paper also include contributions to the stress assessment 685 literature in general and particularly to the occupational health. 686 Findings provide strong theoretical and practical implica687 tions. Respectively, the method makes a valuable contribution 688 to the occupational health stress assessment literature. Ad689 ditionally, practical implications will facilitate the design of 690 holistic occupational health interventions for bus drivers while 691 also guiding authorities interventions aiming to increase road 692 safety. Current ongoing work is deploying this methodology 693 over a larger population in order to perform a comprehensive 694 characterization of sources of stress among professional bus 695 drivers in the city of Porto.

\section{ACKNOWLEDGMENT}

697 We would like to thank Sociedade de Transportes Colectivos 698 do Porto STCP for collaborating in this study, and to Susana 699 Brís, Ph.D., from IEETA/University of Aveiro for her insights 700 in ECG filtering techniques.

\section{REFERENCES}

1] J. L. Tse, R. Flin, and K. Mearns, "Bus driver well-being review: 50 years of research," Transp. Res. Part F Traffic Psychol. Behav., vol. 9, no. 2, pp. 89-114, Mar. 2006

[2] G. W. Evans and S. Carrère, "Traffic congestion, perceived control, and psychophysiological stress among urban bus drivers," J. Appl. Psychol., vol. 76, no. 5, pp. 658-663, Oct. 1991.

[3] K. E. Powell, P. D. Thompson, C. J. Caspersen, and J. S. Kendrick, "Physical activity and the incidence of coronary heart disease," Аnпи. Rev. Public Health, vol. 8, pp. 253-287, May 1987.

[4] M. S. Joshi, V. Senior, and G. P. Smith, "A diary study of the risk perceptions of road users," Health. Risk Soc., vol. 3, no. 3, pp. 261-279, Nov. 2001.

[5] M.-J. Chen and C. Cunradi, "Job stress, burnout and substance use among urban transit operators: The potential mediating role of coping behaviour," Work Stress, vol. 22, no. 4, pp. 327-340, Oct. 2008

[6] N. J. Ward et al., "An evaluation of a lane support system for bus rapid transit on narrow shoulders and the relation to bus driver mental workload," Ergonomics, vol. 49, no. 9, pp. 832-859, Jul. 2006.

[7] R. M. Baevskii, A. P. Berseneva, E. Y. Bersenev, and A. K. Eshmanova, "Use of principles of prenosological diagnosis for assessing the functional state of the body under stress conditions as exemplified by bus drivers," Human Physiol., vol. 35, no. 1, pp. 34-42, Jan. 2009.

[8] R. D. Blasco, J. M. Prieto, and J. M. Cornejo, "Accident probability after accident occurrence," Safety Sci., vol. 41, no. 6, pp. 481-501, Jul. 2003.

[9] A. N. Stephens and J. A. Groeger, "Do emotional appraisals of traffic situations influence driver behaviour?" Behav. Res. Road Safety, pp. 49-62, 2006.

10] M. A. J. Kompier and V. Di Martino, "Review of bus drivers' occupational stress and stress prevention," Stress Med., vol. 11, no. 1, pp. 253-262, Jan. 1995.

1] T. G. M. Vrijkotte, L. J. P. van Doornen, and E. J. C. de Geus, "Effects of work stress on ambulatory blood pressure, heart rate, and heart rate variability," Hypertension, vol. 35, no. 4, pp. 880-886, Apr. 2000.
[12] R. McCraty, M. Atkinson, W. A. Tiller, G. Rein, and A. D. Watkins, 735 "The effects of emotions on short-term power spectrum analysis of 736 heart rate variability," Amer. J. Cardiol., vol. 76, no. 14, pp. 1089-1093, 737 Nov. 1995.

[13] Task Force of The European Society of Cardiology and The North 739 American Society of Pacing and Electrophysiology, "Heart rate variabil- 740 ity: Standards of measurement, physiological interpretation, and clinical 741 use," Eur. Heart J., vol. 17, pp. 354-381, 1996.

[14] J. Choi, B. Ahmed, and R. Gutierrez-Osuna, "Development and evaluation 743 of an ambulatory stress monitor based on wearable sensors," IEEE Trans. 744 Inf. Technol. Biomed., vol. 16, no. 2, pp. 279-286, Mar. 2012.

[15] P. Besson et al., "Effectiveness of physiological and psychological fea- 746 tures to estimate helicopter pilots' workload: A bayesian network ap- 747 proach," IEEE Trans. Intell. Transp. Syst., vol. 14, no. 4, pp. 1872-1881, 748 Dec. 2013.

[16] G. Rigas, Y. Goletsis, and D. I. Fotiadis, "Real-time driver's stress event 750 detection," IEEE Trans. Intell. Transp. Syst., vol. 13, no. 1, pp. 221-234, 751 Mar. 2012.

[17] F. H. Wilhelm and P. Grossman, "Emotions beyond the laboratory: The- 753 oretical fundaments, study design, and analytic strategies for advanced 754 ambulatory assessment," Biol. Psychol., vol. 84, no. 3, pp. 552-569, 755 Jul. 2010.

[18] M. Gunnar and K. Quevedo, "The neurobiology of stress and develop- 757 ment," Annu. Rev. Psychol., vol. 58, pp. 145-173, Jan. 2007.

[19] S. M. Collins, "Emerging methods for the physiological assessment of 759 occupational stress," Work, vol. 17, no. 3, pp. 209-219, Jan. 2001.

[20] S. Shiffman, A. A. Stone, and M. R. Hufford, "Ecological momen- 761 tary assessment," Аnnu. Rev. Clin. Psychol., vol. 4, no. 1, pp. 1-32, 762 Apr. 2008.

[21] J. Cunha et al., "Vital-Jacket: A wearable wireless vital signs monitor for 764 patients' mobility in cardiology and sports," in Proc. Int. Conf. Pervasive- 765 Health, Mar. 2010, pp. 1-2.

766

[22] P. Melillo, M. Bracale, and L. Pecchia, "Nonlinear Heart Rate Variability 767 features for real-life stress detection. Case study: Students under stress 768 due to university examination," Biomed. Eng. Online, vol. 10, no. 1, p. 96, 769 Nov. 2011.

770

[23] J. A. Healey and R. W. Picard, "Detecting stress during real-world driv- 771 ing tasks using physiological sensors," IEEE Trans. Intell. Transp. Syst., 772 vol. 6, no. 2, pp. 156-166, Jun. 2005.

[24] G. W. Evans, G. Johansson, and L. Rydstedt, "Hassles on the job: A study 774 of a job intervention with urban bus drivers," J. Org. Behav., vol. 20, 775 no. 2, pp. 199-208, Mar. 1999.

776

[25] B. Netterstrom and A. M. Hansen, "Outsourcing and stress: physiolog- 777 ical effects on bus drivers," Stress Med., vol. 16, no. 3, pp. 149-160, 778 Apr. 2000.

779

[26] L. W. Rydstedt, G. Johansson, and G. W. Evans, "The human side of the 780 road: Improving the working conditions of urban bus drivers," J. Occup. 781 Health Psychol., vol. 3, no. 2, pp. 161-171, Apr. 1998.

27] G. Johansson, G. W. Evans, L. W. Rydstedt, and S. Carrere, "Job hassles 783 and cardiovascular reaction patterns among urban bus drivers," Int. J. 784 Behav. Med., vol. 5, no. 4, pp. 267-280, Jan. 1998

[28] S. C. Segerstrom and D. B. O'Connor, "Stress, health and illness: Four 786 challenges for the future," Psychol. Health, vol. 27, no. 2, pp. 128-140, 787 2012.

788

[29] L. Schwabe et al., "Stress modulates the use of spatial versus stimulus- 789 response learning strategies in humans," Learn. Mem., vol. 14, no. 1, 790 pp. 109-116, Jan./Feb. 2007.

791

[30] M. R. Hufford, S. Shiffman, J. Paty, and A. A. Stone, "Ecological 792 momentary assessment: Real-world, real-time measurement of patient 793 experience," in Progress in Ambulatory Assessment: Computer-Assisted 794 Psychological and Psychophysiological Methods in Monitoring and Field 795 Studies. Kirkland, WA, USA: Hogrefe \& Huber Publishers, 2001, 796 pp. 69-92.

[31] I. R. Olson and C. Marshuetz, "Remembering 'what' brings along 798 'where' in visual working memory," Perception Psychophys., vol. 67, 799 no. 2, pp. 185-194, Feb. 2005.

[32] J. P. S. Cunha, "PHealth and wearable technologies: A permanent chal- 801 lenge," Stud. Health Technol. Inform., vol. 177, pp. 185-195, 2012.

[33] K. C. Kowalski and P. R. E. Crocker, "Development and validation of the 803 Coping Function Questionnaire for adolescents in sport," J. Sport Exercise 804 Psychol., vol. 23, no. 2, pp. 136-155, Jun. 2001.

[34] M. Kaiseler, R. Polman, and A. Nicholls, "Mental toughness, stress, stress 806 appraisal, coping and coping effectiveness in sport," Pers. Individual 807 Difference, vol. 47, no. 7, pp. 728-733, Nov. 2009.

[35] J. G. P. Rodrigues, A. Aguiar, F. Vieira, J. Barros, and J. P. S. Cunha, 809 "A mobile sensing architecture for massive urban scanning," in Proc. 810 IEEE ITSC, Oct. 2011, pp. 1132-1137. 
812 [36] A. L. Goldberger et al., "PhysioBank, PhysioToolkit, and PhysioNet: 813 Components of a new research resource for complex physiologic signals," 814 Circulation, vol. 101, no. 23, pp. e215-e220, Jun. 2000.

815 [37] S. Akselrod et al., "Power spectrum analysis of heart rate fluctuation: 816 A quantitative probe of beat-to-beat cardiovascular control," Science, 817 vol. 213, no. 4504, pp. 220-222, Jul. 1981.

818 [38] H. B. Mann and D. R. Whitney, "On a test of whether one of two ran819 dom variables is stochastically larger than the other," Ann. Math. Statist., 820 vol. 18, no. 1, pp. 50-60, Mar. 1947.

821 [39] W. H. Kruskal and W. A. Wallis, "Use of ranks in one-criterion vari822 ance analysis," J. Amer. Statist. Assoc., vol. 47, no. 260, pp. 583-621, 823 Dec. 1952

824 [40] M. G. Kendall, "A new measure of rank correlation," Biometrika, vol. 30, 825 no. $1 / 2$, pp. 81-93, Jun. 1938.

826 [41] D. S. Goldstein and I. J. Kopin, "Evolution of concepts of stress," Stress, 827 vol. 10, no. 2, pp. 109-120, Jun. 2007.

828 [42] K. Umetani, D. H. Singer, R. McCraty, and M. Atkinson, "Twenty-four 829 hour time domain heart rate variability and heart rate: Relations to age 830 and gender over nine decades," J. Amer. College Cardiol., vol. 31, no. 3 , 831 pp. 593-601, Mar. 1998.

832 [43] Y. J. Zanstra and D. W. Johnston, "Cardiovascular reactivity in real 833 life settings: Measurement, mechanisms and meaning," Biol. Psychol., 834 vol. 86, no. 2, pp. 98-105, Feb. 2011.

835 [44] I. Myin-Germeys et al., "Experience sampling research in psychopathol836 ogy: Opening the black box of daily life," Psychol. Med., vol. 39, no. 9, 837 pp. $1533-1547$, Sep. 2009.

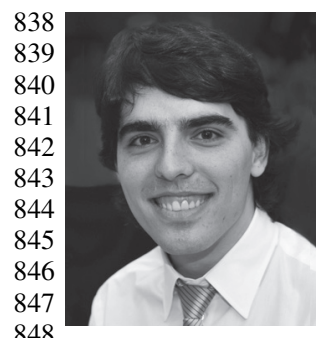

João G. P. Rodrigues (S'11) received the M.Sc. degree in electrical and computer engineering from the University of Porto, Porto, Portugal, in 2009. He is currently working toward the Ph.D. degree with the University of Porto. He develops his work at the Institute for Telecommunications, and the main topics of his thesis are data gathering and mining in intelligent transportation systems. His main research interests include sensor networks and intelligent transportation systems. He received a Doctoral Scholarship from the Portuguese Foundation for Sci849 ence and Technology in 2009.

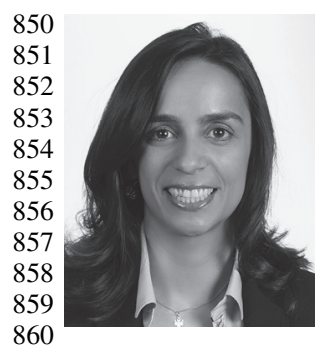

Mariana Kaiseler received the M.Sc. degree in sport science and the Ph.D. degree in sport psychology from the University of Hull, Hull, U.K., and the Postgraduate Certificate in Teaching and Learning in Higher Education from the University of Derby. She is currently a Senior Lecturer in Sports and Exercise Psychology at Carnegie Faculty. She is also an Expert Evaluator for the European Commission and acts as a Peer Reviewer for several prestigious journals in her field. Her research interests include the study of stress, coping, and emotions in sport 861 and occupational health settings. She received funding from a number of 862 universities and external funding bodies, and was awarded the first Marie Curie 863 Fellowship at the Faculty of Psychology, University of Porto, Portugal. She is 864 a Chartered member and Associate Fellow of the British Psychological Society 865 and a Fellow of the Higher Education Academy.

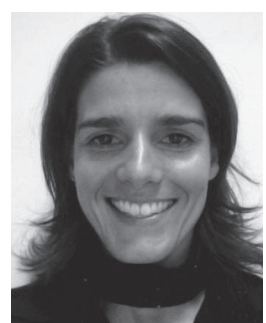

Ana Aguiar (S'94-M'98-S'02-M'09) received the 866 Electrical and Computer Engineering degree from 867 the University of Porto, Porto, Portugal, in 1998, and 868 the Ph.D. in telecommunication networks from the 869 Technical University of Berlin, Berlin, Germany, in 870 2008. Since 2009, she has been an Assistant Pro- 871 fessor with the Faculty of Engineering, University 872 of Porto. She began her career as an RF Engineer 873 working for cellular operators, and she worked at 874 Fraunhofer Portugal AICOS on service-oriented ar- 875 chitectures and wireless technologies applied to am- 876 bient assisted living. She is the author of several papers published and presented 877 in IEEE and ACM journals and conferences, respectively. She contributes to 878 several interdisciplinary projects in the fields of intelligent transportation sys- 879 tems and well being (stress). Her research interests include wireless networking 880 and mobile sensing systems, specifically vehicular networks, crowd sensing, 881 and machine-to-machine communications. She is a Reviewer for several IEEE 882 and ACM conferences and journals.

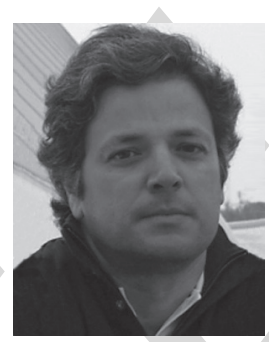

João P. Silva Cunha (S'86-M'90-SM'04) received 884 the Electronics and Telecommunications Engineer- 885 ing degree, the Ph.D. degree, and the "Agregação" 886 degree in electrical engineering from the University 887 of Aveiro, Portugal, in 1989, 1996, and 2009, respec- 888 tively. He is currently an Associate Professor of bio- 889 engineering and electrical and computer engineering 890 with the University of Porto, Portugal; a member 891 of the University of Porto Centre of Competence in 892 Future Cities; and a Senior Researcher at the INESC- 893 TEC Associate Laboratory (http://www.inesctec.pt), 894 where he created the Biomedical Research and Innovation (BRAIN) re- 895 search group and cofounded the Center for Biomedical Engineering Research 896 (C-BER) that aggregates $\sim 30$ researchers. He currently serves as a Codirector 897 of the Bioengineering M.Sc. Program at FEUP and as a Scientific Director 898 of the Carnegie-Mellon|Portugal program (http://www.cmuportugal.org) where 899 he has been a faculty member since 2007. He cofounded in 2007 the spin- 900 off company Biodevices SA (http://www.biodevices.pt) to bring to the market 901 innovative biomedical technology developed for several years in his laboratory. 902 $\mathrm{He}$ is the author or coauthor of more than 250 scientific publications. He is 903 Senior Member of the IEEE, where he joined the Engineering in Medicine and 904 Biology Society (EMBS) in 1986 as a student member.

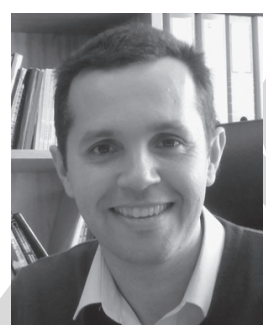

João Barros (S'98-M'04-SM'11) received his un- 906 dergraduate education in electrical and computer 907 engineering from the University of Porto, Porto, 908 Portugal, and Universitaet Karlsruhe, Karlsruhe, 909 Germany, and the Ph.D. degree in electrical engi- 910 neering and information technology from Technische 911 Universitaet Munich, Germany. He is currently an As 912 sociate Professor of electrical and computer engi- 913 neering with the University of Porto and the Found- 914 ing Director of the Institute for Telecommunications 915 (IT), Porto. He also teaches at the Porto Business 916 School and cofounded two recent startups, Streambolico and Veniam, commer- 917 cializing wireless video and vehicular communication technologies, respectively. 918 
AUTHOR QUERY

NO QUERY. 